\title{
Current Challenges and Future Research Directions in Augmented Reality for Education
}

This paper was downloaded from TechRxiv (https://www.techrxiv.org).

\section{LICENSE}

CC BY 4.0

SUBMISSION DATE / POSTED DATE

22-08-2021 / 27-08-2021

\section{CITATION}

Iqbal, Muhammad Zahid; Mangina, Eleni; Campbell, Abraham G. (2021): Current Challenges and Future Research Directions in Augmented Reality for Education. TechRxiv. Preprint.

https://doi.org/10.36227/techrxiv.16369224.v1

$\mathrm{DOI}$

10.36227/techrxiv.16369224.v1 


\title{
Current Challenges and Future Research Directions in Augmented Reality for Education
}

\author{
Muhammad Zahid Iqbal, Member, IEEE, Eleni Mangina, Member, IEEE, and Abraham G. \\ Campbell, Member, IEEE
}

\begin{abstract}
Innovation in formal and practical learning is an accepted progression and its adoption in learning methodologies is a sign that a respective society is open to new technologies, ideas, and, thus, to advancement. The latest innovation in teaching is the use of Augmented Reality. Applications using this technology have been deployed successfully in STEM(Science, Technology, Engineering, and Mathematics) education for delivering the practical and creative parts of the education. Since Augmented Reality technology has already a large volume of published studies about education that reports advantages, limitations, effectiveness, and challenges of $A R$ in education, classifying these projects will allow for a review of the success of Augmented Reality integration in the different educational settings and discover current challenges and future research areas.

The main findings of this paper are the generation of a detailed taxonomy of the current literature which outlines the current challenges, the use of this taxonomy to identify future research areas, and finally to report on the development of two case studies that can highlight the first steps need to address these research areas. The result of this research ultimately is to detail the research gap that is needed to be filled to facilitate real-time touchless hand interaction, kinesthetic learning, machine learning agents with a remote learning pedagogy.
\end{abstract}

Index Terms-Augmented Reality, AR Learning, Human Centered Design, Human Computer Interaction, Collaborative Learning, e-learning, Mixed reality Learning

\section{INTRODUCTION}

$\mathbf{L}$ EARNING assisted with AR technology enables ubiquitous, collaborative and localized learning. It facilitates the magic manifestation of a virtual object displayed in real time in a real world space that can engage a user in the learning process like no other medium has been able to before. AR is an emerging technology with high potential for learning, teaching, and creative training [1].

AR allows for the superimposing of computer-generated virtual 3D objects on top of a real environment in real time [2].

AR-based training has advantages over virtual reality approaches as training takes place in the real world and can have access to real tactile feedback when performing a training task. Other advantages include the instructions and location-dependent information to be directly linked and/or attached to physical objects [4].

AR brings a natural enticement to create attractiveness in the learning process. It can be used with desktops, tablets, smartphones or Head Mounted Displays (HMDs). It is portable and adaptable in different scenarios to enhance the learning process in the traditional classroom, special education classroom, and outside the classroom [5]. The large scale study of EARLS reported the highest ratings on "Usefulness of learning Ecosystems". The fundamental research question this paper seeks to address is that since AR technology has a large volume of published studies about education that reports advantages, limitations, effectiveness and challenges of $A R$ in education, classifying these projects will allow for a review the success of $A R$ integration in the different educational settings and discover current challenges and future research areas.

To address the Current Challenges and Future Research Directions in Augmented Reality for Education, firstly, a definition of the types of AR applications that will be in the review must be defined. So in section 2, categories of AR Learning and scenarios are defined to help understand the current State of the Art.

This is followed by a review in section 3 of current research in this area broken down by domains and then educational level which resulted from surveying and documenting projects in this field discovered through an exhaustive search. These research projects will be future examined in a table listing domains, educational levels and number of subjects that they trialled the technology with, how they have created their AR applications, what devices and tracking technologies they used.

This taxonomy is gives high level overview of the different the user interface complexity with the corresponding level of possible collaboration with either a human or some form of Artificial Intelligence (AI) construct. This construct can take the form of a simple script, an agent based system or machine learning algorithm.

In section 4, based on the review from section 3, this section will identify future research areas. This is followed by section 5 where exploration of these research gaps is given using the implementation of two case studies, which can better illustrate the proposed research directions and highlight the current state of the art in AR. Finally, section 6 will outline the conclusions of this paper.

\section{AR LEARning ApPlications' ClassificAtion}

To capture the current state of the Art for this survey, five types of AR applications are considered based off the definition of the five directions AR education explored by [6] in the field. These categories are as follows:

- AR Books

- AR Educational Games

- AR Discovery-based learning applications 


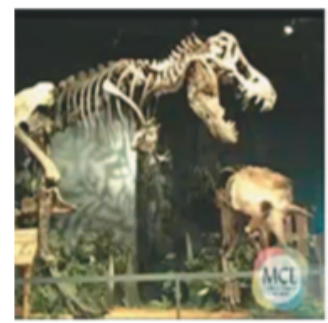

Physical reality

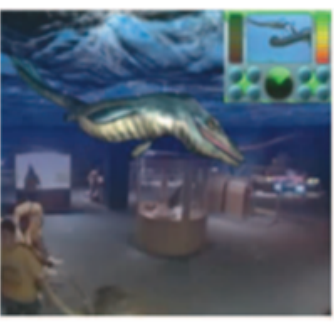

Augmented reality

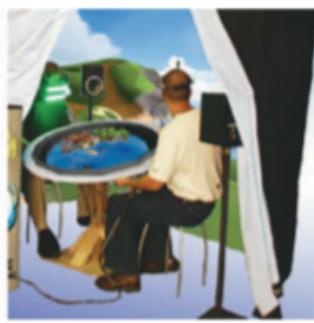

Augmented virtuality

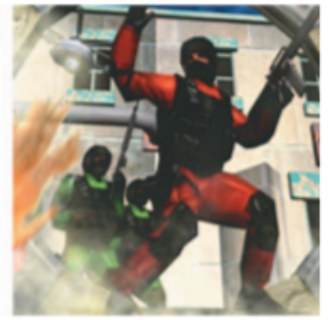

Virtual reality
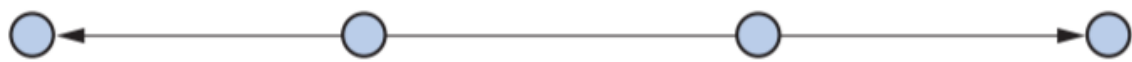

Fig. 1. Milgram's continuum about Physical reality, augmented reality, augmented virtuality and virtual reality [3]

- AR projects that model real world objects for interaction - AR projects exploring skill based training

In terms of a planning methodology, there is no initial specific criteria chosen for selecting papers from any specific journal or conference papers, the search aimed to cover all the reputed AR studies in the education. To achieve this, Keyword search terms were used to find the papers and those keyword searches are listed in Table 1. In defining categories of papers to include or exclude, the choice to include was based on those studies which presented some new applications or new way of using AR in the learning environment and excluded all the survey \& systematic reviews papers from this selection. The survey then further defined categories of the papers according to Educational level and domain.

The studies conducted at the early level up to 5 th grade are considered as Primary School \& from 6th to 8th grades are considered as elementary school. Both Primary \& elementary schools are considered as Early Education in the analysis while upper classes before getting into undergraduate are considered as secondary level (High School). After Secondary, all the upper classes are considered as university (Tertiary Education). The study domains are defined according to the academic subjects addressed in the study.

Finally, this research only included papers that focus on these four AR learning scenarios.

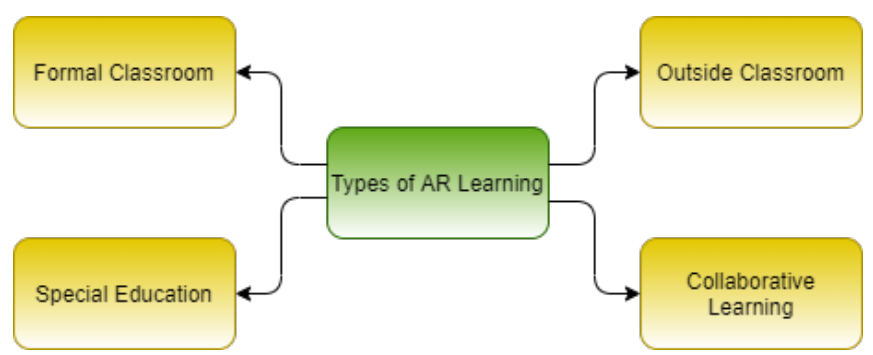

Fig. 2. Types of AR Learning included in this study

This leads us to an application for AR learning in the follow scenarios.

\section{A. AR Learning in Formal classrooms}

In the classroom setting, AR allows students to learn through the combination of both real and computer-generated images [7]. It helps to understand the different topic with different scenarios.

\section{B. AR Learning in Special Education}

AR has the capability to create a learning opportunity for special children by overcoming the physical barriers; it can bring high-quality educational experience to students with learning and physical disabilities as well as the special education classroom, explained in section 3.4.

\section{AR Learning Outside the Classroom}

Using AR smartphone application, AR learning experience can be extended outside the formal classroom which includes self-assisted learning. From field trips to learning in personalized space; AR can create immersive learning opportunities by overlaying digital contents.

\section{AR for Collaborative Learning}

The technology employed with AR does not need to be exclusive to the AR experience. If an educator is looking to model scientific practice, AR provides the opportunity to support the multifaceted world of scientific exploration. The need of collaborative learning has increased recently due to growing need of remote and independent learning where students need to connect with other mates and teachers.

\section{BACKGROUND WORK}

\section{A. Interactive Learning for Early classes}

AR books are the most adopted learning pedagogy in the field of AR learning. This concept involves converting the traditional books into interactive AR books by overlaying 3D contents. [8] reported that the use of AR, regardless of grade level or subject area, allows students to be actively engaged in the learning process. The concept of Augmented Instructions [9] to convert physical book to virtuality and ARGarden [10] as an interactive flower gardening AR system, created a positive learning engagement by adding visualization in the learning process. 


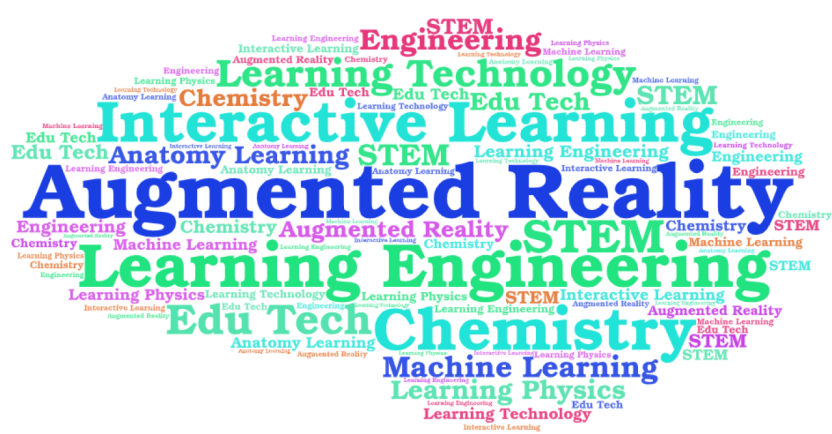

Fig. 3. Keywords cloud of the main terms in AR studies

Similarly, study findings[11] about AR for teaching basic concepts of transportation, Toys++ [12] and AR magical playbook to digitize the traditional storytelling by [13] shows the role of $\mathrm{AR}$ as an engaging factor in the learning process.

Adding more to interaction, an inquiry-based $A R$ learning environment AIBLE [14] manipulates the virtual representations the Sun, the Moon and the Earth which helped to prove the concept of tasks mobilisation and on active learning in AR.

Chen, Chih-Ming et al. [15] used AR to enhance the learner's interest in the Chinese library classification scheme supported using a physical presentation agent. To learn the role of parents in the child learning, the concept of an AR picture [16] identified four behavioral patterns: parent as dominator, child as dominator, communicative child-parent pair, and low communicative child-parent pair.

\section{B. Interactive Learning for Higher Classes}

For high school, Liarokapis, Fotis et al. [17] developed Multimedia Augmented Reality Interface for E-learning (MARIE) to use the potential of AR by superimposing Virtual Multimedia Content (VMC) information in an AR tabletop setting, enabled the user to interact with the VMC composed of three-dimensional objects and animations.

To convert the traditional books into interactive AR books, miBook (Multimedia Interactive Book) reflects the development of a new concept of virtual interpretation of traditional textbooks and audio-visual content[18]. This idea of virtual interpretation showed impact on learning outcomes by adding up visualization to a regular textbook. In a similar approach, ARIES system[19] showed the physical markers as significant impact creators in usability, and perceived enjoyment proved as a much more significant factor than perceived usefulness.

To find the effectiveness of AR, ARCS model (Attention, Relevance, Confidence, Satisfaction) of motivation applied by Wei, Xiaodong et al. [20] using "AR Creative-Classroom" and "AR Creative-Builder". A pilot study proved the proposed teaching scheme significantly improved the learning motivation and student creativity in teaching creative design courses.

To enhance the reading and writing on physical books, SESIL combines book and page recognition, and handwriting recognition using the $\mathrm{AR}$ camera[21]. It is considered as robust and reliable for practical use in education as it yielded positive results. Jeonghye Han [22] conducted an exploratory study to empirically examine children's observations toward the computer- and robot-mediated AR systems which reported positive results in dramatic play and interactive engagement. By mixing the interactive concept maps with AR technology, support of an adequate instructional technique and scaffolds improved the learning outcomes when mixed in to develop a new learning pedagogy [23].

\section{STEM(Science, Technology, Engineering, and Mathematics) Education}

One of the first use cases of AR learning in Secondary Education has been within STEM subjects. AR allows teachers to incorporate new technology and techniques in the classroom which is one of the primary scenarios outlined in section II-A . STEM is taught in secondary and tertiary level education which will be discussed in the overview of Education Level given in section IV-A. Given the link between the technologies that enable AR and STEM it naturally has become one of the primary domains where AR learning is present as discussed in section IV-B. Some of the best examples of AR learning come from looking into the possible use cases in Chemistry, Chen, Yu-Chien et al. [24] investigated how students interact with AR models as compared to physical models to learn amino acids structure in 3D environment. For learning chemistry with ARChemist [25] and through gestures tested in CHEMOTION[26] to provide a virtual interaction with chemicals using hand tracking technology.

Like Chemistry one of the first topics to be covered using AR learning is Astronomy. The use of the AR to learn the earth-sun relationship[27], Earth-Moon System [28] and Live Solar System (LSS)[29] which helped to enhance meaningful engagement learning astronomy concepts and conceptual thinking. AR study to help in learning gravity and planetary motion with an interactive simulation which increased the learning gain significantly and increased positive attitudes of the students [30] .

Visualization techniques of biology processes within AR, allow students to better understand processes that are normally hidden. Nickels, Stefan et al. [31] developed an AR framework ProteinScanAR as an assistive tool for attractive lessons on molecular biology topics using AR. Science Center To Go (SCeTGo)[32] investigated the role of teachers' and students' acceptance and found AR pedagogical efficiency very constructive. Likewise at high school level, there are many AR studies at university level for learning anatomy [33][34] [35][36] [37] \& [38] developed AR anatomy learning systems to learn the exterior to interior of the body by introducing an innovative, hands-on study of the human musculoskeletal system. Also use of leapmotion for 3D body anatomy learning tested to use hand tracking for interacting with 3D models [39] and [40].

The teaching of engineering subjects is a cornerstone of STEM and as such there are multiple examples of AR learning in this area. One summary to view these innovations used 3D web tools in technical and engineering education to help 
the multidimensional augmentation of teaching materials[41] and [42] used in technology and design engineering. Learning Physics through Play Project (LPP) help learning concepts of physics about force and motion[43] and LightUp[44] for learning concepts of electronics like circuit boards, magnets and plastic sheets.

By combining modern mobile AR technology and pedagogical inquiry activities, Chang, Hsin-Yi et al. [45] used AR for teaching Nuclear Power Plant activities with more productive digital visualization. Adding more into learning electronics concepts; ElectARmanual [46] and AR-based flipped learning system[47] helped to achieve better learning outcomes by using the AR guiding mechanism.

Collaboration within an AR environment is an important AR learning scenario as outlined in section IV-H. In keeping with the Chemistry theme, one example of a tangible interaction study which focused on chemistry was conducted using a Tangible User Interface (TUI) called Augmented Chemistry (AC) which reported higher user acceptance by interacting with the 3D models in the lab[48]. Tangible User interface could be one area that helps Collaborative learning but the nature of tangible interaction can require additional resources and in the current COVID crises, alternative touchless interaction approaches could be a better solution to this which will be discussed in section V-A and further in section V-E with a chemistry related case study. Other prominent examples of collaboration using SMALLab found extensive evidence as a powerful approach to learn in a design experiment with Secondary earth science students[49]. As well as the collaboration ability of AR and Internet of Things(IoTs) to create productivity in Engineering education with different scenarios[50]. Finally, AR as a learning tool in the mathematics tested with Construct 3D [51] and GeoAR [52] to support learning the geometry showed a highly positive impact concerning its educational potential.

Field trips are one example of STEM scenarios that require leaving the formal learning environment so suit the outdoor AR use case mentioned in section II-C. Embodied experiences at the field trips for the science classrooms with situated simulations got useful and effective results about student engagement and their connection with the experiential learning from the curriculum [53] .

This potential for Kinesthetic learning discussed more in section V-B has been shown in the AR for training technical people to learn new maintenance and assembly skills for various industries[4]. For a trainee, Interaction with the real world objects, machinery parts while getting the virtual information for learning is the actual advantage of using AR for training.

1) Language Learning: Use of AR for learning language is basically concerned with the formal classroom learning section 2.1, which has been tested successfully in different studies. Use of AR Flash cards for learning about the English Alphabet and animals[54] and an AR based game for Kanji learning[55] reported $\mathrm{AR}$ as a tool of motivation and visual presentation to learning languages. To test the ubiquitous games in the learning approach for language learning, HELLO (Handheld English Language Learning Organization)[56] and another handheld language learning approach [57] showed improved retention of words which increased student satisfaction and attention. Similarly, TeachAR using kinect[58] used for teaching basic English words (colors, shapes, and prepositions) and game based foreign language learning [59]. Use of Microsoft Hololens for vocabulary learning as compared with traditional flashcard based learning, produced higher productivity and effectiveness in learning outcomes[60].

For Language learning at higher classes, A mobile learning tool Explorez[61] for improving the French learning by interacting with objects to improve their French language skills which received acceptance as "useful" and "motivating for students".

2) Collaborative Learning: Collaborative learning approach as defined in the section II-D provides the opportunity of collaboration either teacher-to-student or student-to-student. AR as collaborative learning[62] with SMALLab which is a Student Centered Learning Environment(SCLE) to use interactive digital media in a multimodal sensing framework which reported promising results in social and collaboration aspects. Further in collaborative learning approach, [63] with ARClassNote which is an AR application which allow users to save and share handwritten notes over optical see-through Head Mounted Devices. It makes it easier to achieve communication between instructors and students by sharing written class materials.

AR game concept, "Locatory" introduced by combining a game logic with collaborative game play and personalized mobile augmented reality visualization which provides different perspectives of the the interactive $3 \mathrm{D}$ visualization to learn the content with $\mathrm{AR}$ and identified positive experiences[64]. Further identified collaboration opportunities as discussed in section IV-H and as recommended approach in the section V-F.

3) Environment \& History Learning : Taking AR to location based learning for environment and history as section II-C has proved many successful results. A study of learning environment [65] and location based experiments [66] reported use of AR learning engagement factor by providing virtual media over the top of physical environment. Gurjot Singh et al. developed inquiry based learning application CI-Spy that seeks to engage the students in history using an augmented reality environment [67]. This enabled a comprehensive understanding of historical inquiry for students by combining AR experiences with strategic learning. Lu, Su-Ju et al. chosen game-based learning for a marine learning application with interactive storytelling and interactive game-based test[68]. It helped the students to learn in the virtual context, thus deepening their involvement in the learning experience.

The idea of iARBook captures video input and sends it to the Vuforia which processes frames in real time to detect and find the images in the database[69]. Once it recognizes an image, the related scene is rendered over the video frame as a learning object. By considering the goals of learning achievement and attitude, Ecosystems Augmented Reality Learning System (EARLS) which promote a positive learning attitude among students over Keyboard/Mouse-based 
Computer-Assisted Instruction (KMCAI) approach[70].

\section{Special Education}

AR learning in special education as defined in the section II-B can increase the learning gain by enhancing the representation of content. To explore the AR Learning in Special Education, Luna, Jazheel et al. [71] created 3D Learning Objects using AR for an online learning program which is working for ADHD (Attention Deficit Hyperactivity Disorder) affected students. It further developed as AHA project in extended study as a Web based AR learning system[72]. Their evaluation study highlighted the potential of AR for interactive learning and allowing users to become more engaged with learning content [73]. It provides opportunities for additional educational engagement and process reiteration for learners.

1) MOOC (Massive Open Online Courses) : MOOC (Massive Open Online Courses) represents section II-C as it facilitates learning outside the classrooms. Its importance has been increased recently due to the remote learning adoption through out the world in the emergency situation due to the pandemic. Use of AR in the MOOC has been taken into account to generate interactive and extra appealing online contents which helped to create more productivity by improving visualization, support of individualism and enlightening the interest factor[74] \& [75]. MOOC as remote learning environment can lack the hands on approach of other learning approaches.

2) Technical Training: As discussed in the background section II, AR has been taken as a learning tool in the skill based training. In technical training, in general, the concept of kinesthetic learning is important for hands on learning. The integration of intelligence in the Intelligent Tutoring Systems (ITS) for training users how to assemble components on a computer motherboard, including identifying individual components, and installing on motherboard[76]. This approach of adaptive guidance helped intelligent AR system to show faster performance as compared to an AR training system without intelligent support.

Use of AR for technical training workshop by Joanne Yip et al. [77] to perform the threading task to facilitate better learning helped to improve students' learning experience and understanding of the complex concepts. In the section V-B, this concept was taken into account along with a focus on adding intelligence in the technical skills learning and doing more with a hands-on in resource constraints environment. These training experiences also require the introduction of Authoring Tools to allow for rapid development of customised experiences which are further discussed in section 5 .

3) Authoring Tools: Need of authoring tools is the more important work in the AR learning which is still has open opportunities. There is very little working on authoring tools in AR. In an immersive AR authoring tool where users were authorized to create a dynamic learning environment with AR contents, by allowing users to create content, it is a good approach to address the need for an authoring tool[78]. It reduces the work load for the teacher in creating and managing
AR learning experiences. This can be directly aided by the introduction of different forms of artificial intelligence, one such approach is discussed in section V-C and the background to this work will be discussed in the next section.

\section{E. Multi-Agent Systems}

In both use cases; section II-A and II-C, incorporating the agents can play a significant role. The concept of using interacting intelligent agents in AR can bring more productive results. Use of self-directed animated agents in the AR as AR Puppet[79], validated in AR Lego helped in the autonomous decisions based on their perception of the real environment. A multi-agents system (SRA agent) approach helped to increase the motivate, using the principle of "learn by doing" or kinesthetic learning[80].

Kid Space is an advanced, centralized projection device that creates multi-modal interactivity and intelligently projects AR content across surfaces using a visible agent to help in learning by playing [81]. The initial study showed that children involved actively with the projected character during a math exercise.

FenAR is an AR system following the Problem Based Learning (PBL) approach [82]. The evaluation of this study indicated that integrating AR with PBL activities improved students' learning achievement and increased their positive attitudes towards physics subjects. Alexandru Balog [83] examined the aspects of perceived enjoyment in the students' acceptance of an Augmented Reality Teaching Platform (ARTP) developed using Augmented Reality in School Environments(ARiSE) [84] with test cases in biology and chemistry. This research found perceived usefulness and ease of use as extrinsic and perceived enjoyment as intrinsic for this news learning environment. This paper has recommendation and implementation of machine learning agents in the section $\mathrm{V}-\mathrm{C}$

The below table is showing the AR learning studies according to their domains, educational levels, interaction capacity, collaboration capacity and agency. The User Interaction(UI) is categorized as $0-2,0$ means only placing the $3 \mathrm{D}$ objects in real environment, 2 means a higher interaction like hand interaction or gestures. It has been divided based on simple marker based interaction to real-time touchless hand interaction.

\section{Future Research Areas}

Examining current and past projects using the taxonomy of educational level, domain, tracking, collaboration capacity, agents and interaction level, leads naturally to identifying specific future research areas. The AR application design requirements suggested in [94], being flexible of the content that the teacher can adapt according to the children needs, guide in the exploration to maximize the learning opportunities, in a limited time, and attention to curriculum needs. 


\begin{tabular}{|c|c|c|c|c|c|c|c|c|c|}
\hline Project & Domain & Education Level & Subjects & $\begin{array}{l}\text { Libraries/ } \\
\text { Hardware }\end{array}$ & $\begin{array}{l}\text { Display } \\
\text { Devices }\end{array}$ & $\begin{array}{l}\text { Tracker } \\
\text { Type }\end{array}$ & $\begin{array}{l}\text { UI } \\
\text { Level } \\
(0-2)\end{array}$ & Collaboration & Agent \\
\hline HELLO [56] & $\begin{array}{l}\text { Language } \\
\text { Learning }\end{array}$ & Elementary & 64 & $\begin{array}{l}\text { BlueTooth, } \\
\text { Webcam }\end{array}$ & Smartphone & Marker & 1 & Yes & Yes \\
\hline ARBOOK [85] & Anatomy & Secondary & 211 & Webcam & Desktop PC & Marker & 0 & No & No \\
\hline MIRRACLE [35] & Anatomy & Secondary & - & $\begin{array}{l}\text { Kinect, } \\
\text { Webcam }\end{array}$ & Desktop PC & Gesture & 2 & No & No \\
\hline ARTP [84] & Generic & Elementary & 7 & Webcam & Desktop PC & Marker & 0 & No & No \\
\hline ARGarden [10] & Environment & Primary & - & $\begin{array}{l}\text { ARToolKit, } \\
\text { Webcam }\end{array}$ & Smartphone & Marker & 1 & No & Yes \\
\hline AIBLE [14] & Astronomy & Elementary & 69 & Webcam & Laptop & Marker & 11 & No & No \\
\hline MARIE [17] & Engineering & University & - & Webcam & HMDs & Marker & 1 & No & Yes \\
\hline LPP [43] & Physics & \begin{tabular}{|l} 
University \\
\end{tabular} & 43 & Kinect & Desktop PC & Marker & 1 & Yes & No \\
\hline ARIFLite [41] & Engineering & University & - & $\begin{array}{l}\text { Web3D, } \\
\text { Webcam }\end{array}$ & Web AR & Object & 1 & No & No \\
\hline MAT [76] & $\begin{array}{l}\text { Computer } \\
\text { Science }\end{array}$ & University & 16 & ASPIRE & HMDs & Marker & 2 & No & Yes \\
\hline $\begin{array}{l}\text { Immersive AR Authoring } \\
\text { Tool [78] }\end{array}$ & Engineering & University & 142 & Webcam & Desktop PC & Marker & 0 & No & No \\
\hline SSI on Nuclear Energy [45] & Physics & Secondary & 22 & Webcam & Tablets & Marker & 1 & No & No \\
\hline AHA [72] & $\begin{array}{l}\text { Language } \\
\text { Learning }\end{array}$ & Primary & 117 & Webcam & Web AR & Marker & 0 & No & No \\
\hline CI-Spy [67] & History & Primary & 16 & GPS, Webcam & Tablet/Smartphone & Markerless & 11 & No & No \\
\hline Kanji learning [55] & $\begin{array}{l}\text { Language } \\
\text { Learning }\end{array}$ & Secondary & - & $\begin{array}{l}\text { Wifi, OpenGL, } \\
\text { Webcam }\end{array}$ & PDA & Marker & 0 & Yes & No \\
\hline Locatory [64] & Edu. Game & Secondary & 3 & $\begin{array}{l}\text { Webcam, } \\
\text { GPS }\end{array}$ & Smartphone & Markerless & 0 & No & No \\
\hline EARLS [70] & Enviornment & University & 1211 & $\begin{array}{l}\text { Projector, } \\
\text { Webcam }\end{array}$ & Desktop PC & Gesture & 1 & Yes & No \\
\hline AR marine learning [68] & Enviornment & Secondary & 51 & $\begin{array}{l}\text { Projector, } \\
\text { Webcam }\end{array}$ & Laptop & Marker & 2 & No & No \\
\hline iARBook [69] & Tourism & University & 30 & Vuforia & \begin{tabular}{|l} 
Tablets/ \\
Smartphone
\end{tabular} & Marker & 0 & No & No \\
\hline Construct 3D [86] & Math & Secondary & 14 & $\begin{array}{l}\text { Open Inventor } \\
\text { toolkit }\end{array}$ & HMDs & Object & 1 & Yes & No \\
\hline Kid Space [81] & Math & Primary & 16 & $\begin{array}{l}\text { LiDAR sensor, } \\
\text { Webcam }\end{array}$ & Desktop PC & Object & 1 & No & Yes \\
\hline SaCI [80] & $\begin{array}{l}\text { Discovery } \\
\text { based } \\
\text { learning } \\
\end{array}$ & University & 100 & AmICL & Smartphone & Marker & 2 & No & Yes \\
\hline Toys++ [12] & Generic & Primary & - & \begin{tabular}{|l|}
$\begin{array}{l}\text { Physical object } \\
\text { models }\end{array}$ \\
\end{tabular} & Laptop & $\begin{array}{l}\text { Object } \\
\text { Model }\end{array}$ & 0 & No & No \\
\hline Inquiry-based learning [65] & Environment & Elementary & 57 & \begin{tabular}{|l|} 
Webcam, GPS, \\
Gyro, Compass
\end{tabular} & Smartphone & Markerless & 0 & No & No \\
\hline $\begin{array}{ll}\text { Carmen's } & \text { Anatomy } \\
\text { Learning [33] } & \\
\end{array}$ & Anatomy & Primary & 40 & \begin{tabular}{|l|} 
ARtoolkit, \\
Webcam
\end{tabular} & \begin{tabular}{|l} 
Desktop \\
HMDs
\end{tabular} & Marker & 1 & No & No \\
\hline AR Solar System [27] & Geography & University & 30 & $\begin{array}{l}\text { ARToolkit, } \\
\text { Webcam }\end{array}$ & HMDs & Marker & 0 & No & No \\
\hline EcoMOBILE [66] & Environment & Elementary & 71 & FreshAiR, GPS & Smartphone & Marker & 1 & Yes & No \\
\hline miBook [18] & Storytelling & Primary & 5 & Audiobook & Desktop & Marker & 11 & No & Yes \\
\hline AR Flashcards [54] & $\begin{array}{l}\text { Language } \\
\text { Learning }\end{array}$ & Primary & 42 & Webcam & Tablets/ iPads & Marker & 0 & No & No \\
\hline SMALLab [62] & Chemistry & Secondary & - & Audio Sensing & Desktop & Markerless & 1 & Yes & No \\
\hline CMAR ( [23] & Science & Elementary & 71 & \begin{tabular}{|l} 
Animations, \\
Webcam
\end{tabular} & Tablets & Marker & 1 & No & No \\
\hline Explorez [61] & $\begin{array}{l}\text { Language } \\
\text { Learning }\end{array}$ & University & 11 & ARIS, GPS & Smartphone & Object & 1 & No & No \\
\hline REFLECT [38] & Anatomy & University & 288 & Magic mirror & Desktop & Gesture & 1 & No & No \\
\hline AR-infused robot [22] & $\begin{array}{l}\text { Early } \\
\text { Education }\end{array}$ & Primary & 81 & Webcam & Desktop PC & Marker & 0 & Yes & No \\
\hline ALE [87] & Game & Secondary & 188 & Webcam & Desktop PC & Yes & 1 & Yes & No \\
\hline Daineko, Ye et al. [88] & \begin{tabular}{|l|} 
Learning \\
Physics \\
\end{tabular} & University & - & Leapmotion & Desktop & $\begin{array}{l}\text { Hand } \\
\text { Tracking }\end{array}$ & 1 & No & No \\
\hline $\begin{array}{l}\text { CHEMOTION } \\
{[26]}\end{array}$ & Chemistry & Secondary & 16 & Leapmotion & Desktop & $\begin{array}{l}\text { Hand } \\
\text { Tracking }\end{array}$ & 1 & No & No \\
\hline
\end{tabular}




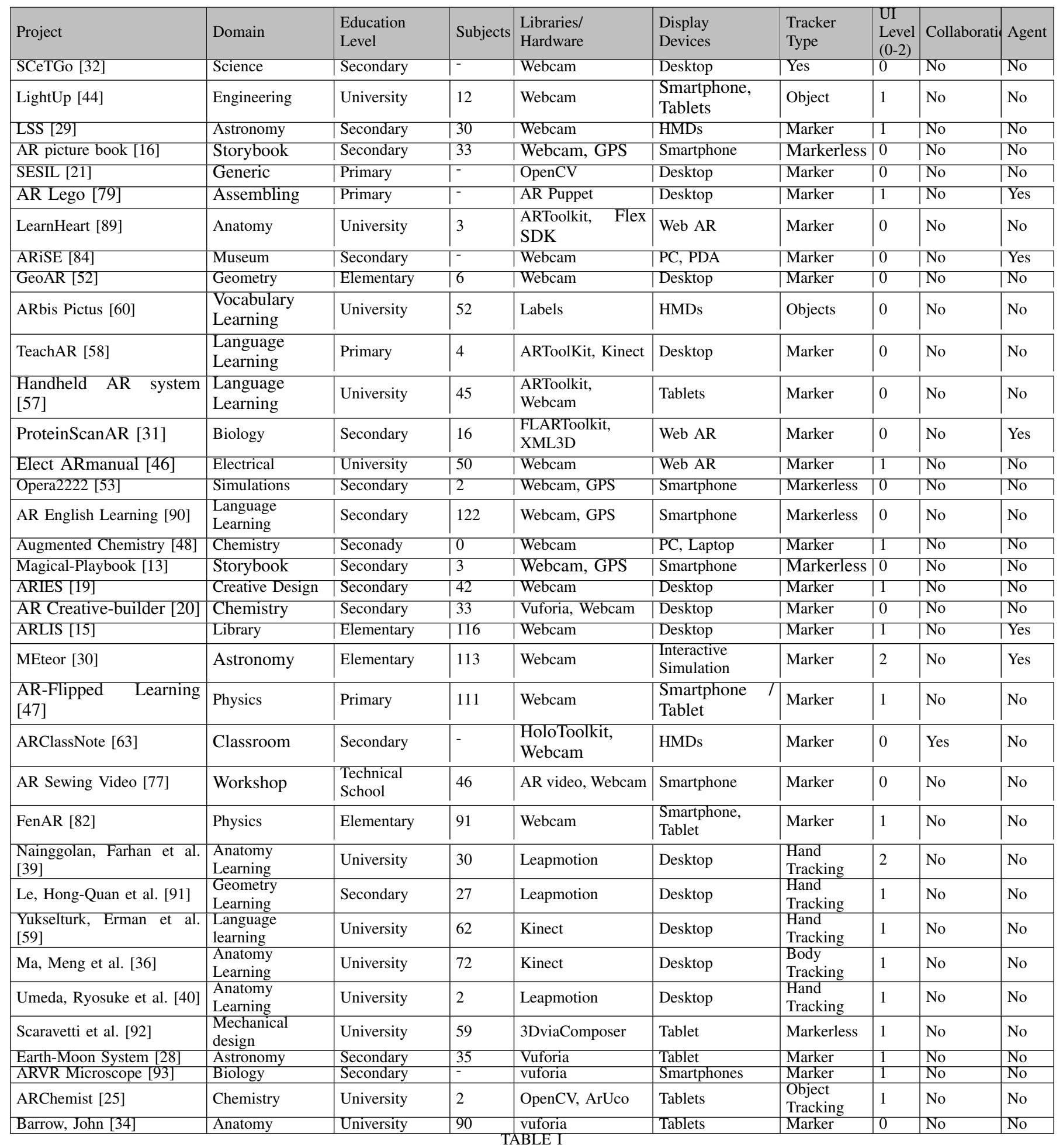

AR STUDIES WITH THEIR STATUS OF DOMAIN, EDUCATION LEVEL, LIBRARIES, DISPLAY DEVICES, USER INTERACTION, COLLABORATION CAPACITY AND AGENTS 


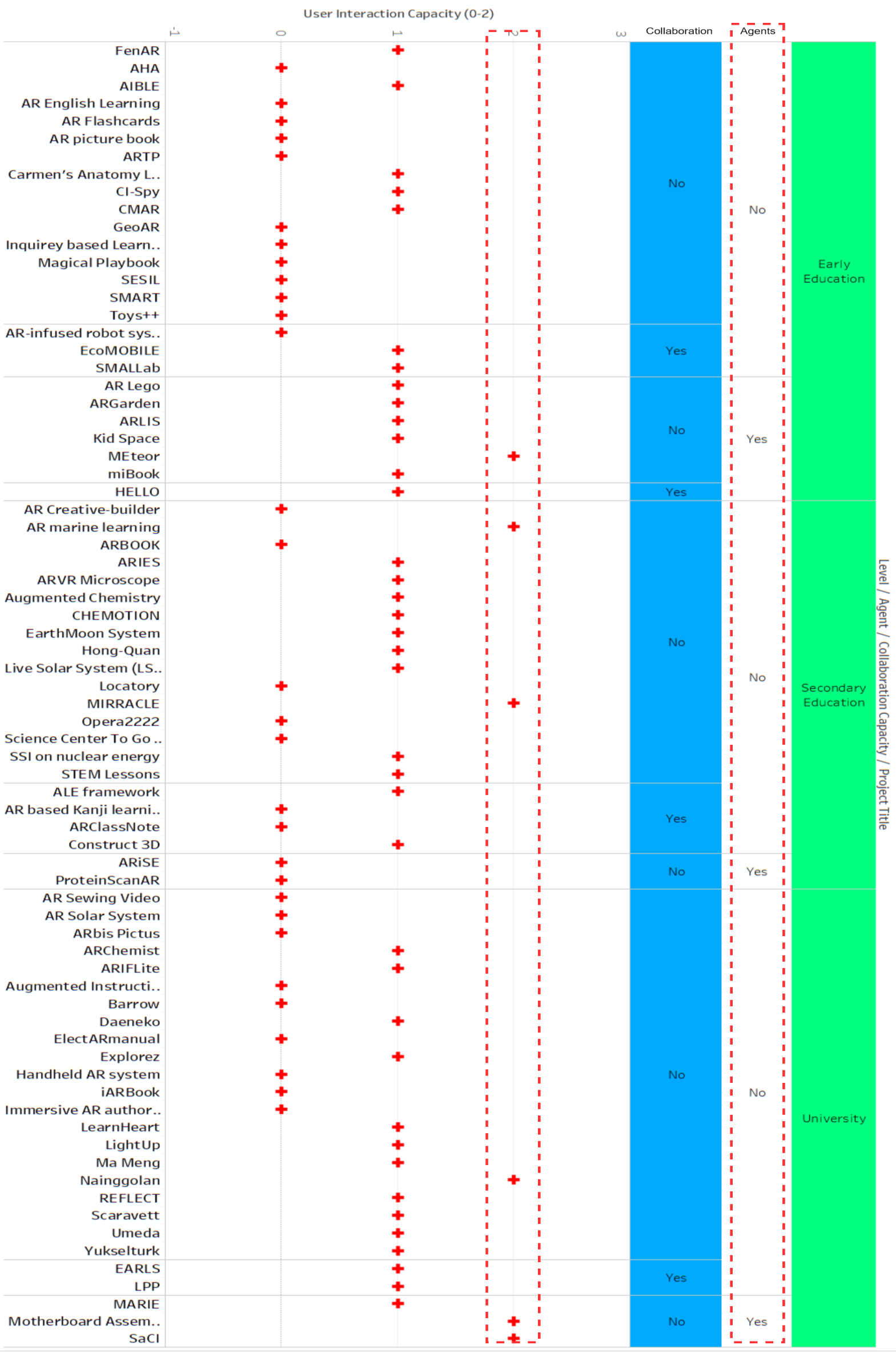

Fig. 4. Graphics representation of different AR applications according to their User Interaction capacity, Collaboration capacity, Agents and educational levelThe dotted red line shows the research gap which is part of further research in this paper. 
This analysis involves 26 studies from primary and elementary level, 22 from secondary school level and 26 from university level. In devices based analysis, Desktop is used in 53\% and Tablets/Smartphones, HMDs, Laptop and WebAR are $25 \%, 15 \%$, and $7 \%$ respectively.

\section{A. Education Level}

It was found with the analysis that AR has been tested and proved equally effective at three educational levels; early (Primary Elementary School), secondary (High School) \& tertiary education (University) presented in the section II. There is a trend towards its use in medical education, however there is a lack of focus on technical or vocational evaluation [77] ) of its use in teaching.

\begin{tabular}{|l|l|}
\hline Educational Level & $\begin{array}{l}\text { AR } \\
\text { Studies }\end{array}$ \\
\hline Early Level (Primary \& Elementary School) & 26 \\
\hline Secondary Level (High School) & 22 \\
\hline Tertiary Level (University) TABLE II & 26 \\
\hline
\end{tabular}

AR Studies Distribution ACCORDIng to EduCATIONAL LEVEL

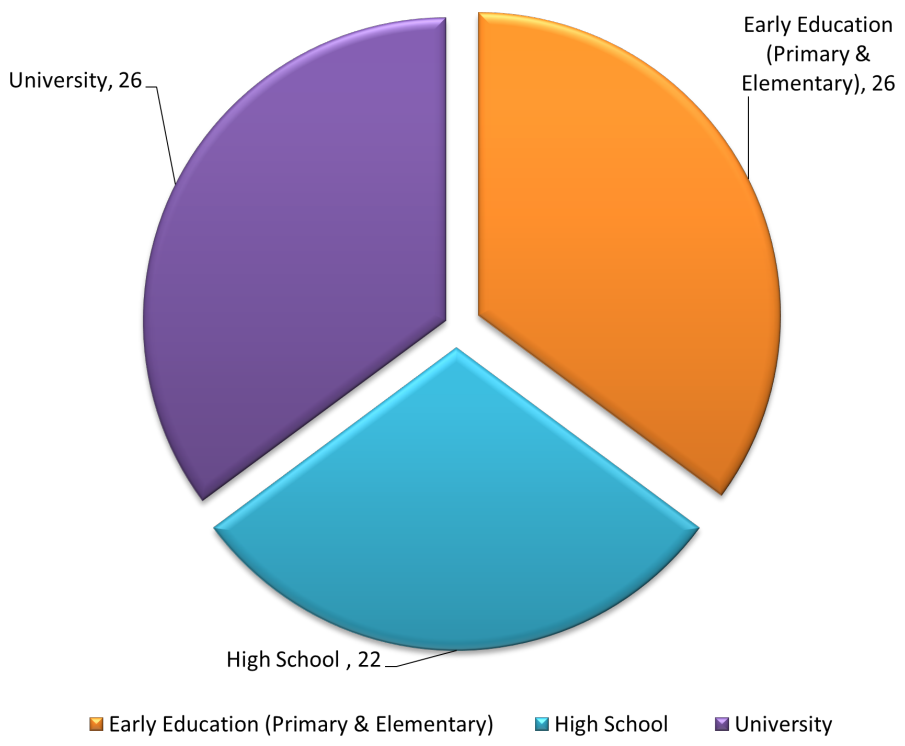

Fig. 5. AR Studies Distribution According to Educational Level

\section{B. Domain}

At early level education (Primary \& Elementary schools) most of the studies are are using using $\mathrm{AR}$ for alphabet learning like [54], vocabulary learning or early level science topics as [14]. At the secondary level (High School) \& tertiary level (University), it has been used as a learning enhancement source for STEM subjects as discussed in III-C. The STEM fields have an amazing future for new AR research. To teach those topics or skill training where actual material is not affordable or not possible in the class setting, use of AR technology can be an effective resource for students.

\section{Experiments conducted to evaluate AR education}

Most of the large scale studies have conducted experiments using control group and experiment group. The focus of the studies are to seek the increase in students attention, getting more relevance to the study topics, gained confidence, and satisfaction as compared to the traditional learning resources. Some studies are evaluated at large scale just like EARLS[70].

\section{Libraries used}

GPS is used in the location based learning applications. Vuforia is used as tracking SDK for most of the studies just like [69]. ARKit, ARCore ARFoundation and AR.js are the other main libraries used for tracking. These are compatible with new series of high-end devices. There are lots of custom made solutions used.

\section{E. Devices}

In the previous studies, Desktop PCs has been used a major device for AR application and then smartphone and HMDs [76] . With the saturation of Smartphone and Tablets, now Tablets and Smartphones are getting higher adoption rates due to portability. Specifically, in the section III-C, there is higher possibility of using a smartphone due to the availability of personal devices.

\begin{tabular}{|l|l|}
\hline Display Device Type & No. of Studies \\
\hline Desktop & 36 \\
\hline Tablets / Smartphones & 22 \\
\hline HMDs & 10 \\
\hline Web AR & 5 \\
\hline
\end{tabular}

AR STUdies Distribution ACCORding to EducAtional LEVEL

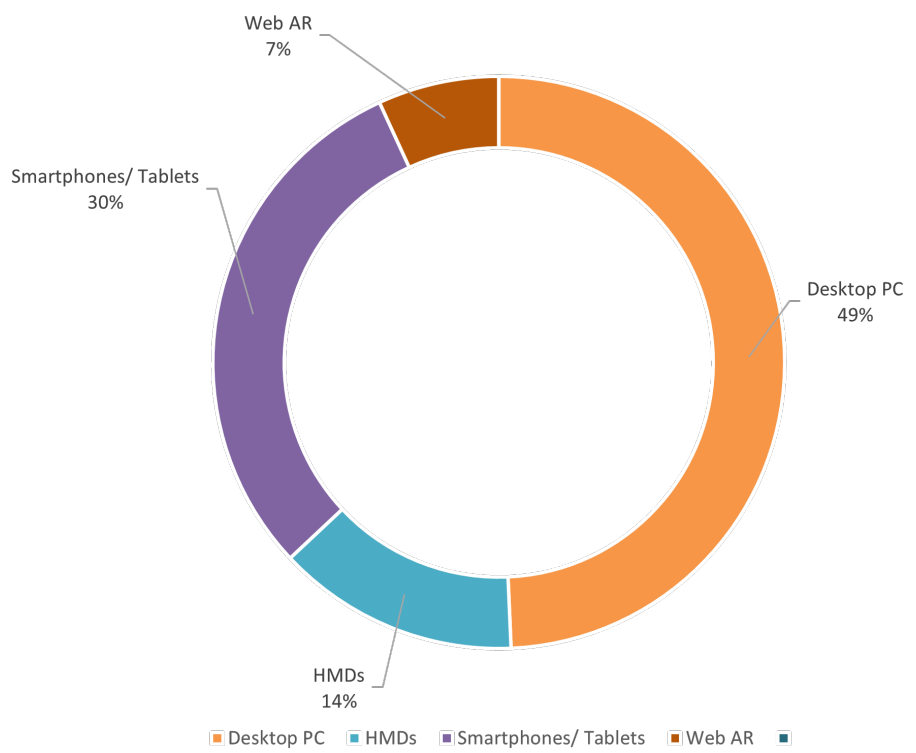

Fig. 7. Distribution of display devices used in AR educational applications

Smartphones \& Tablets are the most reliable devices for AR in education due to affordability as the cost of good HMDs is 


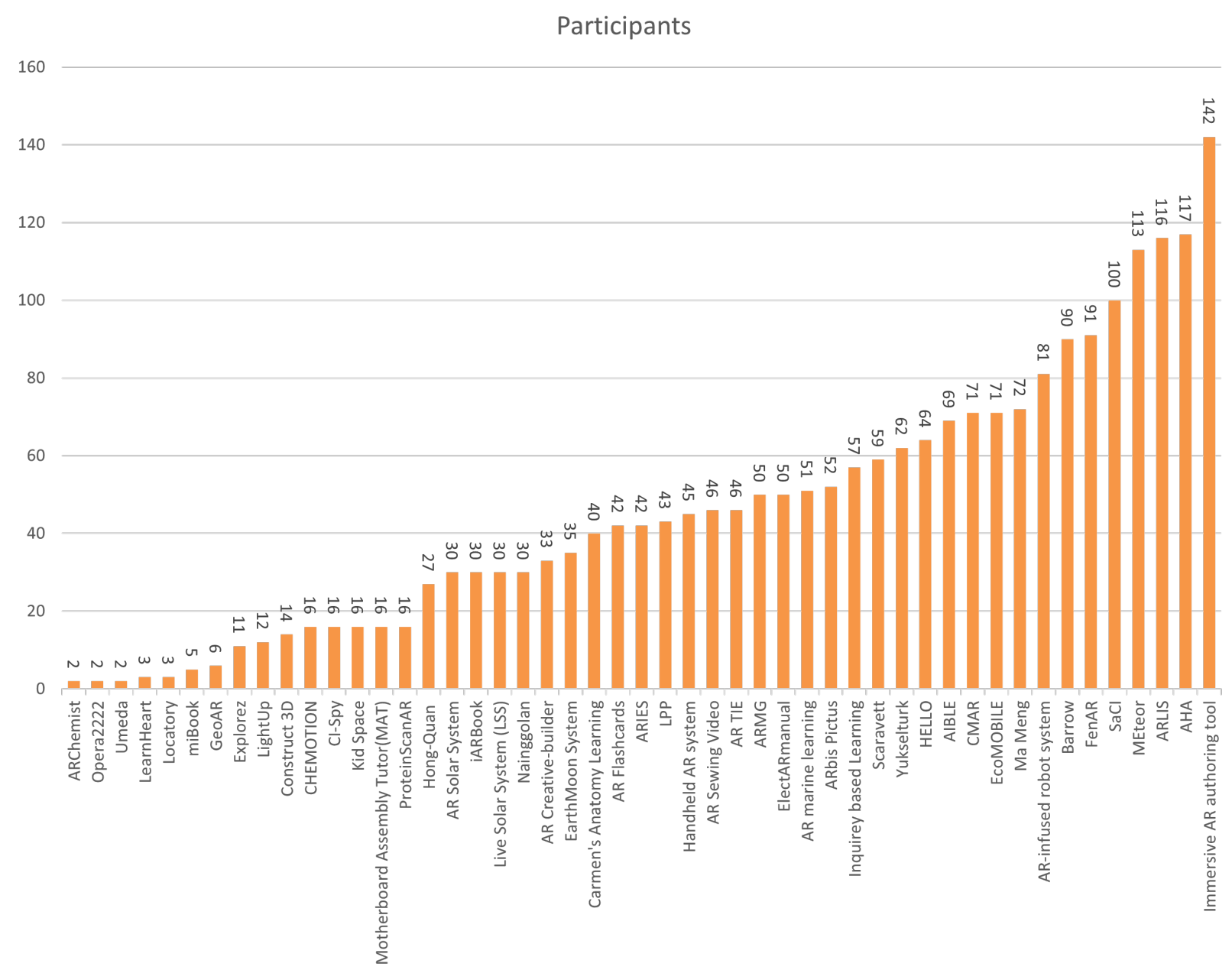

Fig. 6. AR Studies analysis according to the scale of experiments (Participants)

much higher versus smartphones. Legacy desktop is moving more towards smartphones and HMDs like Magic Leap \& Hololens. In the section V, recommendations will be presented using two exemplar case studies; one using a desktop and the other a smartphone.

\section{F. Tracking}

Most of the studies have used markers for tracking which is implemented with Vuforia like [69] and recent studies started using markerless tracking with ARCore or ARKit (moved to plane tracking) in AR application which allows the users to use application without a specified marker. However, use of markers is still important in situations that require high accuracy and some form of tangible interaction with the virtual objects. For studies involved location based learning are using; GPS like field trips study [53]. For devices not supported by ARCore, ARFoundation with ARCore XR Plugin is adopted to get the similar experience. This is important as AR conducted in the class room (II-A requires good lightning conditions which is not always possible. There is lack of studies using the hand tracking technology; presented further with recommendations in the section V.

\section{G. User Interaction}

There is very few studies in the AR learning which are using the hand tracking and gesture control functionality. User interaction has vast opportunity to work in the future. Use of Kinect for anatomy learning is great example of it[37]. There are opportunities to discover new forms of interaction, gesture versus real-time hand interaction (Adopted in section 5) and possibilities of tactile learning. Leapmotion technology is not widely explored yet in AR learning application. Recent innovations in the machine vision based hand tracking technology in the smartphone [95] is also a very recent opportunity to explore which is still going through testing stages to get stability.

\section{H. Collaboration}

Collaborating with the other students and teachers in an AR learning setting is still not a focused area in the previous studies but is a crucial aspect of AR learning as outlined in section II-D. In both formal and outside classroom environments as discussed in section 2 , can be enhanced by collaborative learning.

There are few studies attempted for collaborative learning, like interactive simulation for learning astronomy [30], 
HELLO[56], EARLS by [70] and ARClassNote [63]. This area will be a critical future research area as will be discuss in the lesson from COVID section as this collaboration will now need to be done in many cases remotely. There is need of collaborative learning in the remote learning setup where the teacher can have access to students and students can collaborate in between. This approach is further addressed in section 5.6.

\section{Agents}

From all of the above studies discussed, there are only a few that have actually considered agents (as shown in the Figure 4 with dotted line) presented in section III-E like Kid Space [81] and [82] for problem-based learning. Machine Learning Unity Agents are quite new which have not been effectively implemented in any AR studies for education, discussed in detail in section V-C. Experiments are required to demonstrate this logical next step in the development of AR learning applications where agents can enhance the learning process hence outcomes.

\section{J. Limitations}

AR has been applied in education for visualization, annotation and storytelling in STEM and early education; but there is a lack of intelligent agents, hand tracking and specially real-time hand interaction which is needed for personalized and hands-on learning in STEM in the resource constraint environments. There are very few studies which have performed evaluations at a large scale. Despite the listed advantages, there are certain drawbacks which should be taken into account when building educational solutions with augmented reality: Some teachers may not be able to put these new technologies into practice due to lack of necessary skills. There is a need for instructors willing to engage with new technologies and educational institutions to adapt their infrustructure with applications of AR in the classroom. Hardware availability is a limitation to consider for the uptake of AR in schools, but it is time for governments and policy makers to consider the investment on AR devices given their impact long term for knowledge retention and students' enhanced engagement with educational content and activities. Once the AR in education is well established, hand tracking technology will also be explored in the emerging need of touchless interfaces and real-time hand interaction.

\section{Highlighting Future Directions Using Prototy Pe Case Studies}

This section will focuses on highlighting future directions by the creation of prototype case study applications, that can illustrate the research gaps that need to be addressed. These research gaps include how to approach real-time touchless hand interaction, kinesthetic learning, machine learning agents and remote learning components in the $\mathrm{AR}$ for learning applications. These research gaps that are derived from section 4.3 though to section 4.9 .

The choice to illustrate these research gaps is influenced by the recent health crisis due to COVID-19 pandemic which has caused educational disruption and forced people to re-think about traditional e-learning approaches and innovate new ways. The worldwide adoption of the Suspending Classroom without Suspending Learning policy [96] has created a rush towards the learning technologies and especially focusing on the learning within the personal space. The nature of virus spread through touching created demand for the touchless or contactless technologies which is important in digital transformation including AR educational applications. The future of this research tends more towards finding new types of user interfaces, integration of agents to create more productive learning contexts and new formats of learning pedagogies.

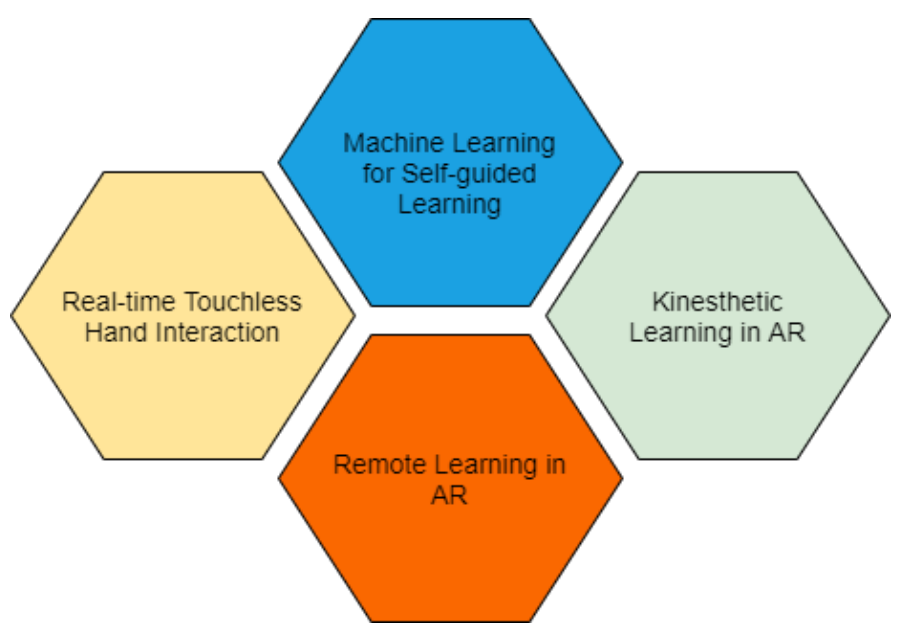

Fig. 8. Four core components of a future research approach in this area

\section{A. Real-time Touchless Hand Interaction (Avoid Touching Devices)}

Interaction is AR application has been tested in different formats like tracking markers, voice and gestures [58] and some other case studies in the section III-C; but there is no research about real-time touchless hand interaction which can help to implement the effective kinesthetic learning. This research gaps ties into our section 4.6 future direction on tracking and section 4.7 on User interaction. In touchless hand interaction, there is nothing to hold in your hands, no buttons to push, no need for mouse, keyboard or touching the display screen, tablets; it is all with the help of depth sensor camera, motion sensor camera, infrared technology and machine learning algorithms which help to interact with the digital elements. There are research studies using kinect and leapmotion tested gesture based touchless interaction with learning objects. Hololens provides gesture based interaction with the 3D environment, as it has been used for vocabulary learning approach[60]. Kinect, leapmotion are working only with the desktop systems and hololens is too costly to afford as a personalized learning solution. The current shift of the learning spaces is moving towards more personalized, affordable and portable which smartphones can be the top most priority for learning technology. Recent development of the Google mediapipe by [97] and manomotion for hand tracking in the smartphones has opened new opportunities for touchless interaction technologies on the affordable devices. 
Touchless interaction by hand tracking technology is of two types; interacting with gestures and real-time hand interaction with the virtual objects.

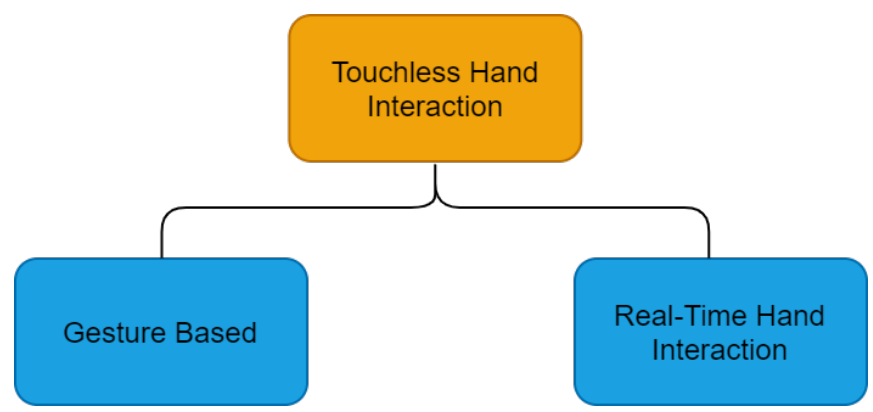

Fig. 9. Types of touchless hand interaction in AR

Figure 10 shows the different options of touchless interaction APIs \& devices which are providing the gesture based interaction ability to the user for interaction in augmented environment. This demonstrates the current state of the art in relation to devices which was discussed previously in section 4.5 .

\begin{tabular}{|l|c|c|c|c|}
\hline \multicolumn{2}{|c|}{ Tracking Device/ SDK/API } & $\begin{array}{c}\text { Initial Release } \\
\text { Date }\end{array}$ & Type of Interaction \\
\hline 1 & $\begin{array}{c}\text { Google } \\
\text { media Pipe }\end{array}$ & I!lil MediaPipe & August 19, 2019 & $\begin{array}{c}\text { Gesture based } \\
\text { interaction }\end{array}$ \\
\hline 2 & Hololens 2 & February 24, 2019 & $\begin{array}{c}\text { Gesture based } \\
\text { interaction }\end{array}$ \\
\hline 3 & ManoMotion & September 2017 & $\begin{array}{c}\text { Gesture based } \\
\text { interaction }\end{array}$ \\
\hline 4 & Hololens 1 & ManOMOTON & 30, 2016 & $\begin{array}{c}\text { Gesture based } \\
\text { interaction }\end{array}$ \\
\hline 5 & LeapMotion & & July 22, 2013 & $\begin{array}{c}\text { Allow gesture } \\
\text { interaction and } \\
\text { hand interaction }\end{array}$ \\
\hline 6 & Kinect & November 4, 2010 & $\begin{array}{c}\text { Gesture based } \\
\text { tracking }\end{array}$ \\
\hline
\end{tabular}

Fig. 10. Devices/ APIs used in augmented reality for interaction to allow hand tracking and gestures

\section{B. Kinesthetic Learning}

Kinesthetic learning is a form of learning which allows the user to "learn by doing task" [98] instead of reading, listening or watching. Specifically in the STEM(Science, technology, engineering, and mathematics) subjects this learning approach is required to help students in learning the concepts. As the distance learning mode has many challenges for both learners and instructors. This is especially for learners during COVID where access to hands-on experiences are sometimes not possible due to social distancing requirements. When considering remote learning for technical and scientific topics; use of hands on work preferred for acquiring better knowledge, kinesthetic learning approach with touchless hand interaction can bring this power in AR learning. It can add positive impact on learning and skills acquisition when integrated effectively. To proceed with the kinesthetic learning approach, there is need of real time hand interaction with the $3 \mathrm{D}$ objects.

\section{Machine Learning Agents for self-guided learning}

Changing imperative of current learning state is moving towards independent learning or self-guided learning. Machine learning and artificial intelligence are playing a big role to achieve this goal in the e-learning solutions by taking a new role as frontier. As discussed in the section IV-I, machine learning agents can transform the future of learning if implemented in the AR application intelligently. It can play a role between the artificial intelligence and human interaction by utilizing the collected data. To integrate the machine learning agents in the proposed research, there are two possible use cases which are taken into account;

- End User Trainer

- Self-Assessment

This research has taken machine learning agents to work in the unity which are following the reinforcement learning concept as explained in the Figure 11.

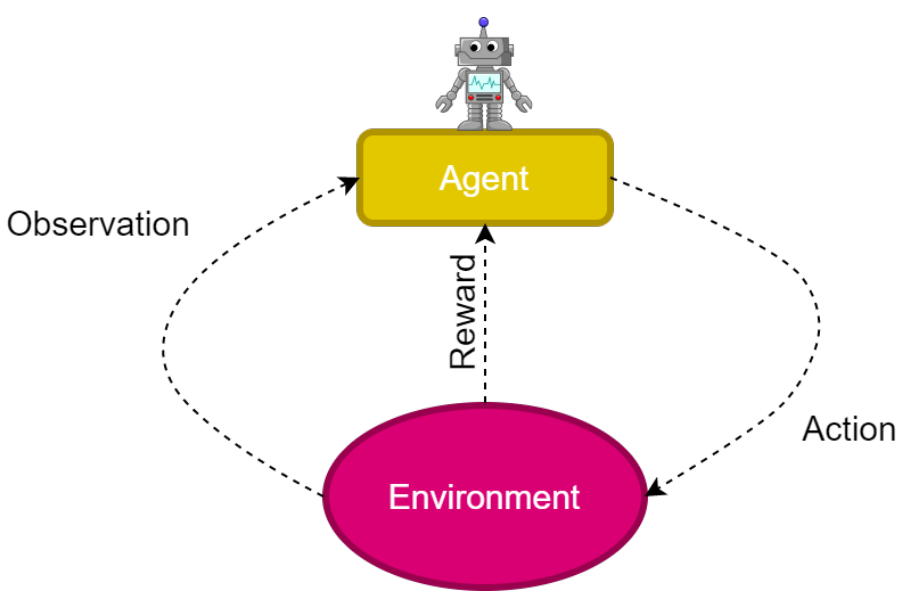

Fig. 11. Process flow of machine learning agent in the AR application, following the reinforcement learning

\section{First Case Study- Learning PC Assembling}

By considering the recommendations made in 5.1, $5.2 \&$ 5.3; a practical implementation was implemented to galvanise this concept. This first case study is focusing on the learning PC assembling for the high school students as a part of necessary computer science education. A motherboard assembly learning case study[76] presented in section 3, demonstrated that showed adding interaction hand to interact with the virtual PC thus allowing hands on learning in virtual environment). The technical components are the unity 3D Engine, Unity machine learning agents(Ml-agents), leapmotion hand tracking SDK, Leapmotion device, hand interaction SDK and 3D models.. 


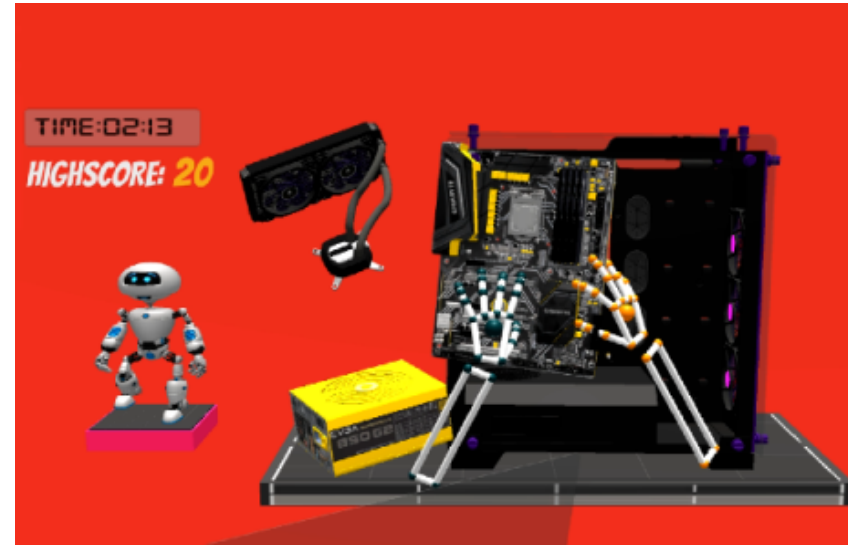

Fig. 12. Touchless hand interaction for learning PC assembly using leapmotion hand tracking

In the figure 12, a demonstration is shown of how the the touchless hand interaction on the desktop PC using leapmotion device is performed. This is a PC assembly learning case study which has been taken as kinesthetic learning approach by allowing the user to do PC assembling tasks with the 3D PC parts using the leapmotion hand tracking.

\section{Environment/Cumulative Reward}

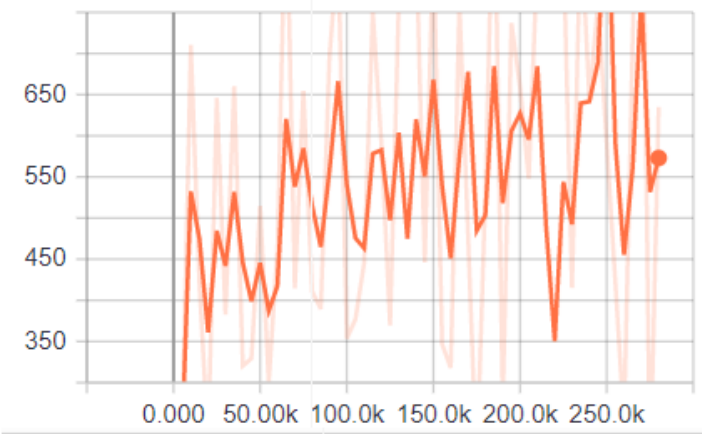

Environment/Episode Length

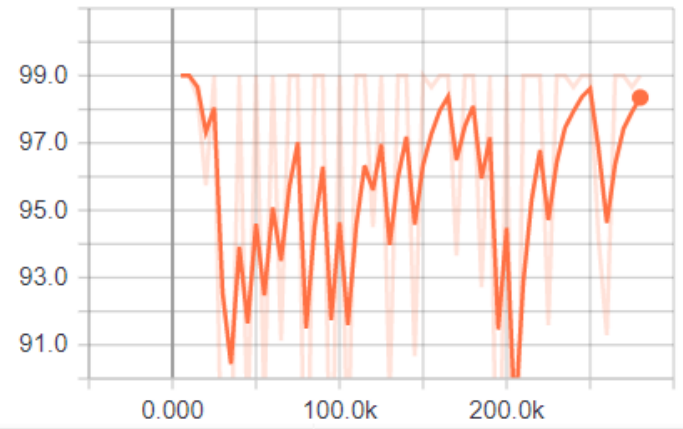

Fig. 13. Tensor flow graphs of machine learning agents training (These graphs are taken from Tensorflow dashboard after training the hand interaction data) First graph is showing the increasing mean rewards on the y axix with respect to the number of steps on $\mathrm{x}$-axis; second one showing the episode time length decrease on the $\mathrm{y}$-axis with respect to the number of steps on $\mathrm{x}$-axis

Using the real-time hand interaction and practicing the "learning by doing" approach, this study is developed for Windows desktop PC as the leapmotion device is not compatible for the android devices. The role of the virtual robot present in the figure 12 is defined as an engaging factor by providing different gestures on completing tasks by user. The ML-agents are used to train the the Neural Network(NN) model which is integrated to the application later as a user trainer based on the pre-trainer models; secondly it is helping in the self-assessment in the testing phase when the user himself is interacting with the system to virtually disassemble the PC.

\section{E. Second Case Study - Learning Chemical Reactions}

Moving away from the desktop environment HMDs with hand tracking in smartphones is a long awaited technology which is now possible with Google mediapipe and manomotion using the neural network and machine learning algorithms. In the second case study, influenced by [48] and STEM related case studies presented in section 3.3; this inspired this concept of virtual chemistry lab. Moving the display device from desktop to smartphone, this case study implemented using the latest interventions in the vision based SDK Manomotion with ARFoundation and ARCore XR Plugin. Manomotion provides real-time 2D and 3D hand tracking without using any external hardware with the smartphone with minimal computing power. The architecture diagram and process of learning flow has been explained in the figure 14. Figure 15 shows the hand tracking in smartphone and touchless hand interaction which allows the user to create chemical reactions by interaction with cubic elements.
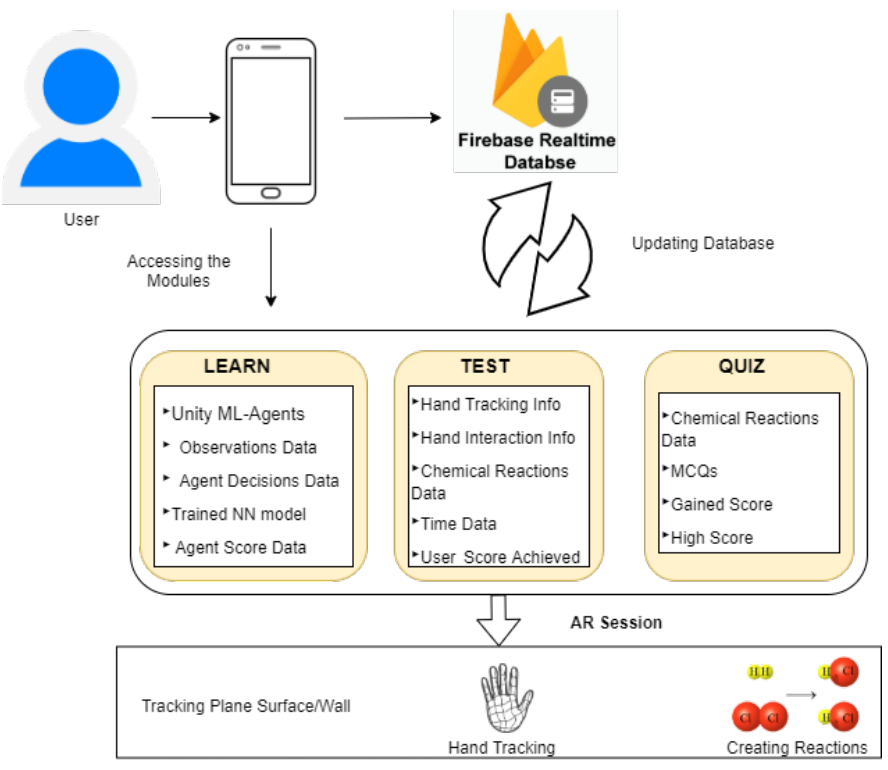

Fig. 14. Architecture Diagram and Working flow of recommended approach in second case study

Using the depth camera, custom made hand and by collaborating with defined gestures of manomation,it allows for the implemented real-time hand interaction with the virtual objects (chemicals/elements). Real-time hand interaction is natural and is a great solution for a health-centric digital interaction. 

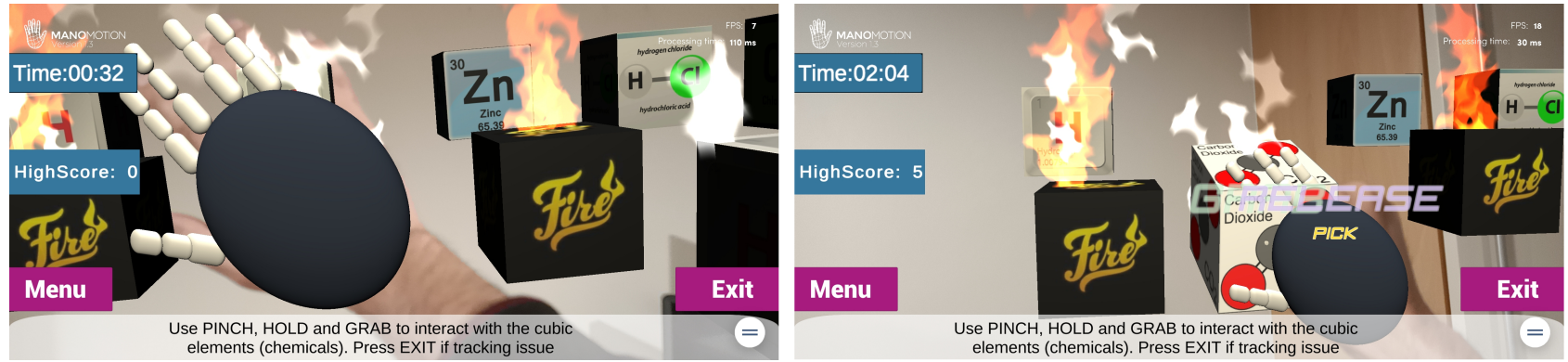

Fig. 15. Touchless hand interaction for learning chemical reactions using hand tracking in smartphones

In this case study, machine learning agents are used to implement the user trainer and self-assessment learning scenarios following the flow explained in the figure 11.

The ML-agent has been taken as a trainer for users by following previously trained models which helps users to learn the chemical reactions and then create the same reactions in the next module where agents help in self-assessment. For the purpose of training agents, data of user hand interaction with the models and success in creating reactions has been taken as behavior collections and rewards assigning. The trained Neural Network(NN) models integrated in the AR application in Unity which work as a trainer module for users before going to learning by interacting with $3 \mathrm{D}$ objects.

\section{Environment/Cumulative Reward}

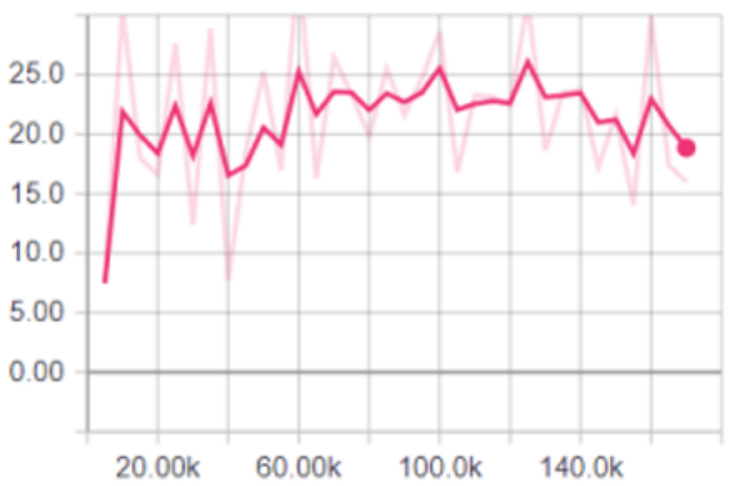

Environment/Episode Length

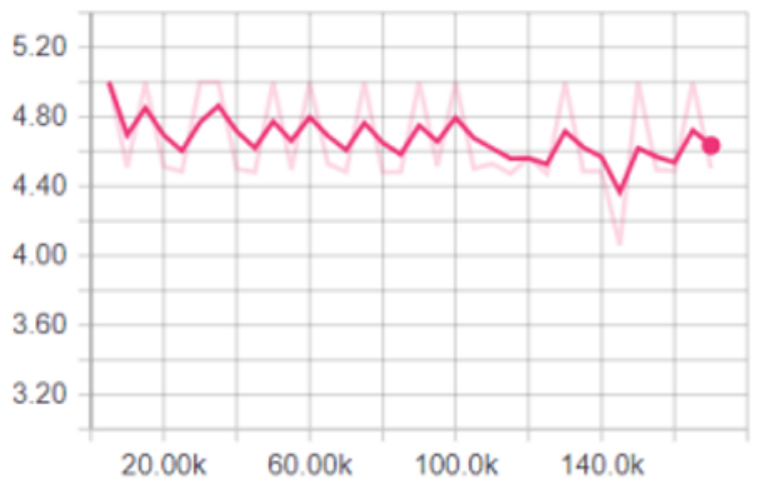

Fig. 16. Graphs are showing the Agent training for chemical reactions;First graph is showing the increasing mean rewards on the y axix with respect to the number of steps on $\mathrm{x}$-axis; second one showing the episode time length decrease on the $y$-axis with respect to the number of steps on $\mathrm{x}$-axis
Figure 16 the tensorflow graphs of the trained model which is further integrated in the unity app to be used as trainer role. As explained in the figure 14, users will start with the LEARN module where machine learning agents will help users to learn creating chemical reactions using the previously trained $\mathrm{NN}$ model. In the next step, the process moves into the TEST module where hand tracking is enabled using Manomotion technology and allows users to create chemical reactions using hand interaction. After completion of the TEST module, the user enters the QUIZ module which has all assessment related MCQs which completes a learning cycle from assisted learning to hand-on learning and assessment.

\section{F. Empowering Remote Learning in $A R$}

The landscape of education has dramatically changed since the start of the COVID-19 pandemic, which provided a directional shift towards blended learning. Through AR applications, learning becomes dynamic and user centered. All of the previous studies in AR are implemented in the context of the classroom environment but it has not been explored in the personal devices outside the classroom with an organized system like ARETE [99]. The shift of the current learning scenario has created a need of implementing new types of learning pedagogies using collaboration factor as mentioned in section 4.8. The concept of remote learning has been adopted by integrating Firebase database. The remote learning approach has been adopted in the second case study, section $\mathrm{V}-\mathrm{E}$; it is developed for the smartphones and involved with remote user authentication and post-test learning assessment integrated with a Google Firebase database which is helping to control and access the learning outcome of the users.

This approach allows for the conducting of a remote evaluation, as explained in [100] in virtual reality application for skill training. This design would start to address the research gap highlighted in section 4.3. This application has the capacity to be extended as a collaboration and authoring tool between the students and instructor, and further allows for large scale remote evaluation with 100's if not 1000's of participants. COVID-19 has led a global acceleration in remote learning adoption as the realisation sets in that this is the "new normal' [101].

\section{Conclusions}

From STEM to foreign language learning, immersive technologies have proven to be an effective and result oriented 
tool in creating more interactive learning environments. In particular, AR enables more sophisticated, interactive and discovery-based forms of learning. Portability and compatibility of the contents between the devices matters, however, practically it is not possible to provide the AR contents with the same quality on all devices.

The next logical step in AR-based learning discovered from reviewing the current literature is the development of applications which can enable personalized learning materials for both students and teachers. Future challenges for the technology are that of user acceptance, proving its educational effect, and further development of the frameworks to development these innovative applications. As the cost of hardware and software decreases, the AR technology will become more affordable and thus allowing it to be widespread at all educational levels.

For personalized learning, AR inherently through its virtual nature facilities personal experience with ease, as every viewer can have a customised personal experience without affecting other users. AR thus can be used to create a personalized learning system that is far more relevant to the user than any other technology. It allows the students to visualize different concepts in real time and interact with them in a digital world. It makes knowledge more accessible through experiential learning opportunities. Based on the previous studies and current progress in technology, it can be said, AR can produce amazing results in the education of STEM subjects. Virtual lab based practical learning exercises where augmented objects can fill the need for physical material. This allows the user can gain some the sense of the how physical objects would interact even if they are in a deprived education system that could not afford the real physical learning materials.

The future areas of research have been further demonstrated in two STEM related case studies to further illustrate the future research areas identified earlier in the paper. These cases studies highlighted what components a system would require to facilitate real-time touchless hand interaction, kinesthetic learning, machine learning agents with a remote learning pedagogy. With integration of these components, AR can offer new possibilities for innovative learning in resource constrained environments to save the learning material cost.

\section{REFERENCES}

[1] H.-K. Wu, S. W.-Y. Lee, H.-Y. Chang, and J.-C. Liang, "Current status, opportunities and challenges of augmented reality in education," Computers \& education, vol. 62, pp. 41-49, 2013.

[2] E. Mangina, "3d learning objects for augmented/virtual reality educational ecosystems," in 2017 23rd International Conference on Virtual System \& Multimedia (VSMM). IEEE, 2017, pp. 1-6.

[3] C. E. Hughes, C. B. Stapleton, D. E. Hughes, and E. M. Smith, "Mixed reality in education, entertainment, and training," IEEE computer graphics and applications, vol. 25, no. 6, pp. 24-30, 2005.

[4] S. Webel, U. Bockholt, T. Engelke, N. Gavish, M. Olbrich, and C. Preusche, "An augmented reality training platform for assembly and maintenance skills," Robotics and Autonomous Systems, vol. 61, no. 4, pp. 398-403, 2013.

[5] M. Antonioli, C. Blake, and K. Sparks, "Augmented reality applications in education," The Journal of Technology Studies, vol. 40, 052014.

[6] S. C.-Y. Yuen, G. Yaoyuneyong, and E. Johnson, "Augmented reality: An overview and five directions for ar in education," Journal of Educational Technology Development and Exchange (JETDE), vol. 4, no. 1, p. 11, 2011.
[7] G. Chang, P. Morreale, and P. Medicherla, "Applications of augmented reality systems in education," in Society for Information Technology \& Teacher Education International Conference. Association for the Advancement of Computing in Education (AACE), 2010, pp. 1380-1385.

[8] M. Billinghurst and A. Duenser, "Augmented reality in the classroom," Computer, vol. 45, no. 7, pp. 56-63, 2012.

[9] K. Asai, H. Kobayashi, and T. Kondo, "Augmented instructions-a fusion of augmented reality and printed learning materials," in Advanced Learning Technologies, 2005. ICALT 2005. Fifth IEEE International Conference on. IEEE, 2005, pp. 213-215.

[10] S. Oh and W. Woo, "Argarden: Augmented edutainment system with a learning companion," in Transactions on edutainment I. Springer, 2008, pp. 40-50.

[11] R. Freitas and P. Campos, "Smart: a system of augmented reality for teaching 2 nd grade students," in Proceedings of the 22nd British HCI Group Annual Conference on People and Computers: Culture, Creativity, Interaction-Volume 2. BCS Learning \& Development Ltd., 2008, pp. 27-30.

[12] L. Simeone and S. Iaconesi, "Toys++ ar embodied agents as tools to learn by building," in 2010 10th IEEE International Conference on Advanced Learning Technologies. IEEE, 2010, pp. 649-650.

[13] A. B. Tomi and D. R. A. Rambli, "An interactive mobile augmented reality magical playbook: Learning number with the thirsty crow," Procedia computer science, vol. 25, pp. 123-130, 2013.

[14] S. Fleck, G. Simon, and J. C. Bastien, "[poster] aible: An inquiry-based augmented reality environment for teaching astronomical phenomena," in Mixed and Augmented Reality-Media, Art, Social Science, Humanities and Design (ISMAR-MASH'D), 2014 IEEE International Symposium on. IEEE, 2014, pp. 65-66.

[15] C.-M. Chen and Y.-N. Tsai, "Interactive augmented reality system for enhancing library instruction in elementary schools," Computers \& Education, vol. 59, no. 2, pp. 638-652, 2012.

[16] K.-H. Cheng and C.-C. Tsai, "Children and parents' reading of an augmented reality picture book: Analyses of behavioral patterns and cognitive attainment," Computers in Education, vol. 72, pp. 302-312, 2014.

[17] F. Liarokapis, P. Petridis, P. F. Lister, M. White et al., "Multimedia augmented reality interface for e-learning (marie)," World Transactions on Engineering and Technology Education, vol. 1, no. 2, pp. 173-176, 2002.

[18] A. Dias, “Technology enhanced learning and augmented reality: an application on multimedia interactive books," 2009.

[19] R. Wojciechowski and W. Cellary, "Evaluation of learners' attitude toward learning in aries augmented reality environments," Computers \& Education, vol. 68, pp. 570-585, 2013.

[20] X. Wei, D. Weng, Y. Liu, and Y. Wang, "Teaching based on augmented reality for a technical creative design course," Computers \& Education, vol. 81, pp. 221-234, 2015.

[21] G. Margetis, P. Koutlemanis, X. Zabulis, M. Antona, and C. Stephanidis, "A smart environment for augmented learning through physical books," in 2011 IEEE International Conference on Multimedia and Expo. IEEE, 2011, pp. 1-6.

[22] J. Han, M. Jo, E. Hyun, and H. jeong So, "Examining young children's perception toward augmented reality-infused dramatic play." Educational Technology Research and Development, vol. 63, no. 3, pp. 455-474, 2015.

[23] C.-H. Chen, Y.-Y. Chou, and C.-Y. Huang, "An augmented-reality-based concept map to support mobile learning for science," Asia-pacific Education Researcher, vol. 25, no. 4, pp. 567-578, 2016.

[24] Y.-C. Chen, "A study of comparing the use of augmented reality and physical models in chemistry education," in Proceedings of the 2006 ACM international conference on Virtual reality continuum and its applications. ACM, 2006, pp. 369-372.

[25] M. P. Woźniak, A. Lewczuk, K. Adamkiewicz, J. Józiewicz, M. Malaya, and P. Ladonski, "Archemist: Aiding experimental chemistry education using augmented reality technology," in Extended Abstracts of the 2020 CHI Conference on Human Factors in Computing Systems, 2020, pp. 1-6.

[26] H. S. Al-Khalifa, "Chemotion: A gesture based chemistry virtual laboratory with leap motion," Computer Applications in Engineering Education, vol. 25, no. 6, pp. 961-976, 2017.

[27] B. E. Shelton and N. R. Hedley, "Using augmented reality for teaching earth-sun relationships to undergraduate geography students," in Augmented Reality Toolkit, The First IEEE International Workshop, vol. 8. IEEE, 2002. 
[28] C. Lindner, A. Rienow, and C. Jürgens, "Augmented reality applications as digital experiments for education-an example in the earth-moon system," Acta Astronautica, vol. 161, pp. 66-74, 2019.

[29] A. K. Sin and H. B. Zaman, "Live solar system (lss): Evaluation of an augmented reality book-based educational tool," in 2010 International Symposium on Information Technology, vol. 1. IEEE, 2010, pp. 1-6.

[30] R. Lindgren, M. Tscholl, S. Wang, and E. Johnson, "Enhancing learning and engagement through embodied interaction within a mixed reality simulation," Computers \& Education, vol. 95, pp. 174-187, 2016.

[31] S. Nickels, H. Sminia, S. C. Mueller, B. Kools, A. K. Dehof, H.-P Lenhof, and A. Hildebrandt, "Proteinscanar-an augmented reality web application for high school education in biomolecular life sciences," in 2012 16th International Conference on Information Visualisation. IEEE, 2012, pp. 578-583.

[32] H. Buchholz, C. Brosda, R. Wetzel et al., "Science center to go: A mixed reality learning environment of miniature exhibits," in Proceedings of the â Learning with ATLAS@CERNâ Workshops Inspiring Science Learning EPINOIA, 2010, pp. 85-96.

[33] C. Juan, F. Beatrice, and J. Cano, "An augmented reality system for learning the interior of the human body," in 2008 Eighth IEEE International Conference on Advanced Learning Technologies. IEEE, 2008, pp. 186-188.

[34] J. Barrow, C. Forker, A. Sands, D. O'Hare, and W. Hurst, "Augmented reality for enhancing life science education," in VISUAL, 2019, pp. $7-12$.

[35] T. Blum, V. Kleeberger, C. Bichlmeier, and N. Navab, "mirracle: An augmented reality magic mirror system for anatomy education," in 2012 IEEE Virtual Reality Workshops (VRW). IEEE, 2012, pp. 115-116.

[36] M. Ma, P. Fallavollita, I. Seelbach, A. M. Von Der Heide, E. Euler, J. Waschke, and N. Navab, "Personalized augmented reality for anatomy education," Clinical Anatomy, vol. 29, no. 4, pp. 446-453, 2016

[37] M. Meng, P. Fallavollita, T. Blum, U. Eck, C. Sandor, S. Weidert, J. Waschke, and N. Navab, "Kinect for interactive ar anatomy learning," in 2013 IEEE international symposium on mixed and augmented reality (ISMAR). IEEE, 2013, pp. 277-278.

[38] R. Barmaki, K. Yu, R. Pearlman, R. Shingles, F. Bork, G. M. Osgood, and N. Navab, "Enhancement of anatomical education using augmented reality: An empirical study of body painting," Anatomical sciences education, 2019

[39] F. L. Nainggolan, B. Siregar, and F. Fahmi, "Anatomy learning system on human skeleton using leap motion controller," in 2016 3 rd International Conference on Computer and Information Sciences (ICCOINS). IEEE, 2016, pp. 465-470.

[40] R. Umeda, M. A. Seif, H. Higa, and Y. Kuniyoshi, "A medical training system using augmented reality," in 2017 International Conference on Intelligent Informatics and Biomedical Sciences (ICIIBMS). IEEE, 2017, pp. 146-149.

[41] F. Liarokapis, N. Mourkoussis, M. White, J. Darcy, M. Sifniotis, P. Petridis, A. Basu, and P. F. Lister, "Web3d and augmented reality to support engineering education," World Transactions on Engineering and Technology Education, vol. 3, no. 1, pp. 11-14, 2004.

[42] T. Thornton, J. V. Ernst, and A. C. Clark, "Augmented reality as a visual and spatial learning tool in technology education," Technology and Engineering Teacher, vol. 71, no. 8, pp. 18-21, 2012.

[43] N. Enyedy, J. A. Danish, G. Delacruz, and M. Kumar, "Learning physics through play in an augmented reality environment," International journal of computer-supported collaborative learning, vol. 7, no. 3, pp. 347-378, 2012.

[44] J. Chan, T. Pondicherry, and P. Blikstein, "Lightup: an augmented, learning platform for electronics," in IDC, 2013.

[45] H.-Y. Chang, H.-K. Wu, and Y.-S. Hsu, "Integrating a mobile augmented reality activity to contextualize student learning of a socioscientific issue," British Journal of Educational Technology, vol. 44, no. 3, pp. E95-E99, 2013.

[46] J. Martín-Gutiérrez, P. Fabiani, W. Benesova, M. D. Meneses, and C. E. Mora, "Augmented reality to promote collaborative and autonomous learning in higher education," Computers in Human Behavior, vol. 51, pp. 752-761, 2015.

[47] S.-C. Chang and G.-J. Hwang, "Impacts of an augmented reality-based flipped learning guiding approach on students' scientific project performance and perceptions," Computers \& Education, vol. 125, pp. 226-239, 2018

[48] M. Fjeld and B. M. Voegtli, "Augmented chemistry: An interactive educational workbench," in Mixed and Augmented Reality, 2002.
ISMAR 2002. Proceedings. International Symposium on. IEEE, 2002, pp. 259-321.

[49] D. Birchfield and C. Megowan-Romanowicz, "Earth science learning in smallab: A design experiment for mixed reality," International Journal of Computer-Supported Collaborative Learning, vol. 4, no. 4, pp. 403-421, 2009.

[50] A. Probst and M. Ebner, "Introducing augmented reality at secondary colleges of engineering," DS 93: Proceedings of the 20th International Conference on Engineering and Product Design Education (EPDE 2018), Dyson School of Engineering, Imperial College, London. 6th - 7th September 2018, pp. 714-719, 2018.

[51] H. Kaufmann, "Collaborative augmented reality in education," Institute of Software Technology and Interactive Systems, Vienna University of Technology, 2003.

[52] T. G. Kirner, F. M. V. Reis, and C. Kirner, "Development of an interactive book with augmented reality for teaching and learning geometric shapes," in 7th Iberian Conference on Information Systems and Technologies (CISTI 2012). IEEE, 2012, pp. 1-6.

[53] G. Liestøl, O. Smørdal, and O. Erstad, "Stem-learning by means of mobile augmented reality. exploring the potential of augmenting classroom learning with situated simulations and practical activities on location," Edulearn15 proceedings. The international academy of technology, education and development, 2015.

[54] A. H. Safar, A. A. Al-Jafar, and Z. H. Al-Yousefi, "The effectiveness of using augmented reality apps in teaching the english alphabet to kindergarten children: A case study in the state of kuwait." Eurasia Journal of Mathematics, Science \& Technology Education, vol. 13, no. 2, 2017.

[55] D. Wagner and I. Barakonyi, "Augmented reality kanji learning," in Proceedings of the 2nd IEEE/ACM International Symposium on Mixed and Augmented Reality. IEEE Computer Society, 2003, p. 335.

[56] T.-Y. Liu and Y.-L. Chu, "Using ubiquitous games in an english listening and speaking course: Impact on learning outcomes and motivation," Computers \& Education, vol. 55, no. 2, pp. 630-643, 2010 .

[57] M. E. C. Santos, T. Taketomi, G. Yamamoto, M. M. T. Rodrigo, C. Sandor, H. Kato et al., "Augmented reality as multimedia: the case for situated vocabulary learning," Research and Practice in Technology Enhanced Learning, vol. 11, no. 1, p. 4, 2016.

[58] C. S. C. Dalim, A. Dey, T. Piumsomboon, M. Billinghurst, and S. Sunar, "Teachar: An interactive augmented reality tool for teaching basic english to non-native children," in 2016 IEEE International Symposium on Mixed and Augmented Reality (ISMAR-Adjunct). IEEE, 2016, pp. 82-86.

[59] E. Yukselturk, S. Altıok, and Z. Başer, "Using game-based learning with kinect technology in foreign language education course," Journal of Educational Technology \& Society, vol. 21, no. 3, pp. 159-173, 2018.

[60] A. Ibrahim, B. Huynh, J. Downey, T. Höllerer, D. Chun, and J. O'donovan, "Arbis pictus: A study of vocabulary learning with augmented reality," IEEE transactions on visualization and computer graphics, vol. 24, no. 11, pp. 2867-2874, 2018.

[61] B. Perry, "Gamifying french language learning: a case study examining a quest-based, augmented reality mobile learning-tool," Procedia-Social and Behavioral Sciences, vol. 174, pp. 2308-2315, 2015.

[62] D. Birchfield, T. Ciufo, and G. Minyard, "Smallab: a mediated platform for education," in ACM SIGGRAPH 2006 Educators program. ACM, 2006, p. 33.

[63] J. Choi, B. Yoon, C. Jung, and W. Woo, "Arclassnote: Augmented reality based remote education solution with tag recognition and shared hand-written note," in 2017 IEEE International Symposium on Mixed and Augmented Reality (ISMAR-Adjunct). IEEE, 2017, pp. 303-309.

[64] M. Specht, S. Ternier, and W. Greller, "Dimensions of mobile augmented reality for learning: a first inventory," 2011

[65] T. H. Chiang, S. J. Yang, and G.-J. Hwang, "Students' online interactive patterns in augmented reality-based inquiry activities," Computers \& Education, vol. 78, pp. 97-108, 2014.

[66] A. M. Kamarainen, S. Metcalf, T. Grotzer, A. Browne, D. Mazzuca, M. S. Tutwiler, and C. Dede, "Ecomobile: Integrating augmented reality and probeware with environmental education field trips," Computers \& Education, vol. 68, pp. 545-556, 2013.

[67] G. Singh, D. A. Bowman, D. Hicks, D. Cline, J. T. Ogle, A. Johnson, R. Zlokas, T. Tucker, and E. D. Ragan, "Ci-spy: designing a mobile augmented reality system for scaffolding historical inquiry learning," in 2015 IEEE International Symposium on Mixed and Augmented 
Reality-Media, Art, Social Science, Humanities and Design. IEEE, 2015, pp. 9-14.

[68] S.-J. Lu and Y.-C. Liu, "Integrating augmented reality technology to enhance children's learning in marine education," Environmental Education Research, vol. 21, no. 4, pp. 525-541, 2015.

[69] M. W. Bazzaza, B. Al Delail, M. J. Zemerly, and J. W. Ng, "iarbook: An immersive augmented reality system for education," in Teaching, Assessment and Learning (TALE), 2014 International Conference on. IEEE, 2014, pp. 495-498.

[70] K.-F. Hsiao, N.-S. Chen, and S.-Y. Huang, "Learning while exercising for science education in augmented reality among adolescents," Interactive learning environments, vol. 20, no. 4, pp. 331-349, 2012.

[71] J. Luna, R. Treacy, T. Hasegawa, A. Campbell, and E. Mangina, "Words worth learning-augmented literacy content for adhd students," in 2018 IEEE Games, Entertainment, Media Conference (GEM). IEEE, 2018, pp. 1-9.

[72] E. Mangina, G. Chiazzese, and T. Hasegawa, "Aha: Adhd augmented (learning environment)," in 2018 IEEE International Conference on Teaching, Assessment, and Learning for Engineering (TALE). IEEE, 2018, pp. 774-777.

[73] G. Chiazzese, E. Mangina, A. Chifari, G. Merlo, R. Treacy, and C. Tosto, "The aha project: An evidence-based augmented reality intervention for the improvement of reading and spelling skills in children with adhd," in International Conference on Games and Learning Alliance. Springer, 2018, pp. 436-439.

[74] J. Chauhan, S. Taneja, and A. Goel, "Enhancing mooc with augmented reality, adaptive learning and gamification," in 2015 IEEE 3rd International Conference on MOOCs, Innovation and Technology in Education (MITE). IEEE, 2015, pp. 348-353.

[75] A. G. Campbell, K. Santiago, D. Hoo, and E. Mangina, "Future mixed reality educational spaces," in 2016 Future Technologies Conference (FTC). IEEE, 2016, pp. 1088-1093.

[76] G. Westerfield, A. Mitrovic, and M. Billinghurst, "Intelligent augmented reality training for motherboard assembly," artificial intelligence in education, vol. 25, no. 1, pp. 157-172, 2015.

[77] J. Yip, S.-H. Wong, K.-L. Yick, K. Chan, and K.-H. Wong, "Improving quality of teaching and learning in classes by using augmented reality video," Computers \& Education, vol. 128, pp. 88-101, 2019.

[78] H.-K. Jee, S. Lim, J. Youn, and J. Lee, "An augmented reality-based authoring tool for e-learning applications," Multimedia Tools and Applications, vol. 68, no. 2, pp. 225-235, 2014.

[79] I. Barakonyi, T. Psik, and D. Schmalstieg, "Agents that talk and hit back: Animated agents in augmented reality," in Proceedings of the 3rd IEEE/ACM International Symposium on Mixed and Augmented Reality. IEEE Computer Society, 2004, pp. 141-150.

[80] L. Chamba-Eras and J. Aguilar, "Augmented reality in a smart classroom-case study: Saci," IEEE Revista Iberoamericana de Tecnologias del Aprendizaje, vol. 12, no. 4, pp. 165-172, 2017.

[81] G. J. Anderson, S. Panneer, M. Shi, C. S. Marshall, A. Agrawal, R. Chierichetti, G. Raffa, J. Sherry, D. Loi, and L. M. Durham, "Kid space: Interactive learning in a smart environment," in Proceedings of the Group Interaction Frontiers in Technology. ACM, 2018, p. 8.

[82] F. Mustafa and M. Tuncel, "Integrating augmented reality into problem based learning: The effects on learning achievement and attitude in physics education," Computers \& Education, p. 103635, 2019.

[83] A. Balog and C. Pribeanu, "The role of perceived enjoyment in the students' acceptance of an augmented reality teaching platform: A structural equation modelling approach," Studies in Informatics and Control, vol. 19, no. 3, pp. 319-330, 2010.

[84] M. Bogen, J. Wind, and A. Giuliano, "Arise-augmented reality in school environments," in European Conference on Technology Enhanced Learning. Springer, 2006, pp. 709-714.

[85] J. Ferrer-Torregrosa, J. Torralba, M. Jimenez, S. García, and J. Barcia, "Arbook: Development and assessment of a tool based on augmented reality for anatomy," Journal of Science Education and Technology, vol. 24, no. 1, pp. 119-124, 2015.

[86] H. Kaufmann, D. Schmalstieg, and M. Wagner, "Construct3d: a virtual reality application for mathematics and geometry education," Education and information technologies, vol. 5, no. 4, pp. 263-276, 2000.

[87] C. Brom, V. Šisler, and R. Slavík, "Implementing digital game-based learning in schools: augmented learning environment of 'europe 2045'," Multimedia systems, vol. 16, no. 1, pp. 23-41, 2010.

[88] Y. A. Daineko, M. Ipalakova, D. Tsoy, Z. B. Baurzhan, Y. K. Yelgondy, Z. Z. Bolatov, A. Seitnur, and A. Zhaksylyk, "Use of new technologies in physics studying," in Proceedings of the 5th International Conference on Engineering and MIS, 2019, pp. 1-5.
[89] M. Kiourexidou, K. Natsis, P. Bamidis, N. Antonopoulos, E. Papathanasiou, M. Sgantzos, and A. Veglis, "Augmented reality for the study of human heart anatomy," International Journal of Electronics Communication and Computer Engineering, vol. 6, no. 6, p. $658,2015$.

[90] S. Küçük, R. M. Yỳlmaz, and Y. Gökta, "Augmented reality for learning english: Achievement, attitude and cognitive load levels of students." Education \& Science/Egitim ve Bilim, vol. 39, no. 176, 2014.

[91] H.-Q. Le and J.-I. Kim, "An augmented reality application with hand gestures for learning 3d geometry," in 2017 IEEE International Conference on Big Data and Smart Computing (BigComp). IEEE, 2017, pp. 34-41.

[92] D. Scaravetti and D. Doroszewski, "Augmented reality experiment in higher education, for complex system appropriation in mechanical design," Procedia CIRP, vol. 84, pp. 197-202, 2019.

[93] X. Zhou, L. Tang, D. Lin, and W. Han, "Virtual \& augmented reality for biological microscope in experiment education," Virtual Reality \& Intelligent Hardware, vol. 2, no. 4, pp. 316-329, 2020.

[94] L. Kerawalla, R. Luckin, S. Seljeflot, and A. Woolard, “"making it real": exploring the potential of augmented reality for teaching primary school science," Virtual Reality, vol. 10, no. 3, pp. 163-174, 2006.

[95] M. Z. Iqbal and A. Campbell, "The emerging need for touchless interaction technologies," Interactions, vol. 27, no. 4, pp. 51-52, 2020.

[96] W. Zhang, Y. Wang, L. Yang, and C. Wang, "Suspending classes without stopping learning: China's education emergency management policy in the covid-19 outbreak," 2020.

[97] C. Lugaresi, J. Tang, H. Nash, C. McClanahan, E. Uboweja, M. Hays, F. Zhang, C.-L. Chang, M. G. Yong, J. Lee et al., "Mediapipe: A framework for perceiving and processing reality," 2019.

[98] A. Begel, D. D. Garcia, and S. A. Wolfman, "Kinesthetic learning in the classroom," ACM SIGCSE Bulletin, vol. 36, no. 1, pp. 183-184, 2004.

[99] S. Masneri, A. Domínguez, F. Wild, J. Pronk, M. Heintz, J. Tiede, A. Nistor, G. Chiazzese, and E. Mangina, "Work-in-progress-arete-an interactive educational system using augmented reality," in 2020 6th International Conference of the Immersive Learning Research Network (iLRN). IEEE, 2020, pp. 283-286.

[100] C. Botha-Ravyse, T. H. Fr, M. Luimula, P. Markopoulos, F. Bellalouna et al., "Towards a methodology for online vr application testing," in 2020 11th IEEE International Conference on Cognitive Infocommunications (CogInfoCom). IEEE, 2020, pp. $000295-000298$.

[101] M. Z. Iqbal and A. G. Campbell, "Covid-19 and challenges for learning-technology adoption in pakistan," Interactions, vol. 28, no. 2, pp. 8-9, 2021.

Muhammad Zahid Iqbal Muhammad Zahid Iqbal is $\mathrm{PhD}$ researcher at School of Computer Science, University College Dublin, Ireland. His area of interest is Augmented reality with touchless interaction technologies, Artificial intelligence and machine learning agents for STEM education. His $\mathrm{PhD}$ research involves the investigating challenges and opportunities of the touchless hand interaction and machine learning agents to support kinesthetic learning in augmented reality.

Eleni Mangina Eleni Mangina is Associate Professor at School of Computer Science, University College Dublin, Ireland. She received her $\mathrm{PhD}$ from University of Strathclyde (UK), Department of Electronic and Electrical Engineering, working on Agent-based applications for intelligent data interpretation. She is Principal Investigator of ARETE project funded by European Union's Horizon 2020 research.

Abraham G. Campbell Abraham G. Campbell is Assistant Professor at School of Computer Science, University College Dublin, Ireland. He received his $\mathrm{PhD}$ in Computer Science from University College Dublin. He is working as head of UCD VR Lab. His research involves Virtual Reality, Augmented Reality, Artificial Intelligence, Computer Graphics and Human-computer Interaction. 